DOE/ID-10603

September 1997

\title{
Hydropower Resources at Risk: The Status of Hydropower Regulation and Development - 1997
}

\section{Idaho National Engineering Laboratory}

\section{U.S. Department of Energy • /daho Operations Office}

$+2$




\section{DISCLAIMER}

This report was prepared as an account of work sponsored by an agency of the United States Government. Neither the United States Government nor any agency thereof, nor any of their employees, makes any warranty, express or implied, or assumes any legal liability or responsibility for the accuracy, completeness, or usefulness of any infomation, apparatus, product or process disclosed, or represents that its use would not infringe privately owned rights. References herein to any specific commercial product, process, or service by trade name, trademark, manufacturer, or otherwise, does not necessarily constitute or imply its endorsement, recommendation, or favoring by the United States Government or any agency thereof. The views and opinions of authors expressed herein do not necessarily state or reflect those of the United States Government or any agency thereof. 


\section{DISCLAMISR}

Portions of this doecoment myy be illeaible in electronic irogge products. Imoges are produced from the best available origioal documenter 


\title{
Hydropower Resources at Risk: The Status of Hydropower Regulation and Development-1997
}

\author{
Richard T. Hunt \\ Judith A. Hunt \\ Richard Hunt Associates, Inc. \\ 7038 Harbour Village Court, Suite 201 \\ Annapolis, MD 21403
}

September 1997

\author{
Prepared for the \\ U.S. Department of Energy \\ Assistant Secretary for Energy Efficiency and Renewable Energy \\ DOE Idaho Operations Office \\ Contract DE-AF07-97ID10901
}




\section{EXECUTIVE SUMMARY}

This report documents today's hydropower licensing and development status based on published data as follows:

- Federal Energy Regulatory Commission (FERC) databases, maintained by FERC's Office of Hydropower Licensing, of: (1) operating FERC-regulated projects, federal projects, and known unlicensed projects; (2) surrendered licenses; and, (3) recent licensing and relicensing actions;

- Energy Information Administration (EIA) data on installed capacity and generation from 1949 through 1995 for the various resources used to produce electricity in the U. S.; and,

- FERC licensing orders, and environmental assessments or environmental impact statements for each individual project relicensed since 1980.

The analysis conducted to prepare this paper includes the effects of all FERC hydropower licensing actions since 1980, and applies those findings to estimate the costs of hydropower licensing and development activity for the next 15 years. It also quantifies the national cost of hydropower regulation.

The future estimates are quite conservative. The are presented in 1996 dollars without speculating on the effects of future inflation, license surrenders, conditions imposed through open-ended license articles, license terms greater than 30 years, or low water years. Instead, they show the most directly predictable influences on licensing outcomes using actual experiences since ECPA (after 1986). For example, post-ECPA data indicate that two-thirds of all relicensed projects lost generation and five percent of all pre-relicensing generation was lost at relicensing. Therefore, similar influences are applied to the projects to be relicensed between 1996 and 2010 to predict total capacity, generation, and dollar losses for this period. And since every peaking project relicensed since 1986 has had its ability to meet peak power demands reduced or eliminated, similar outcomes are applied to peaking projects now being relicensed or those with licenses that expire in the near future. Total costs are projected over an assumed 30 -year license life. 
The findings also debunk some popular environmental myths. For example, the myth that new conventional hydropower development requires the construction of numerous large dams. Of the 345 new conventional hydro projects placed in service since 1986, there have been only two new dams over 100 feet high constructed for hydropower projects. These were developed for municipalities in Alaska and Washington where the licenses were issued in 1985-86. Of the remaining 343 new post-ECPA projects, 19 involved the construction of low diversions and 324 were developed using an existing dam or without any dam.

ECPA requires that the FERC consult with a host of other federal and state resource agencies. Increasingly, conditions that these agencies recommend for licensing are accepted as mandatory by the FERC. For example, in a number of cases the FERC has mandated the construction of expensive fish ladders and screening devices at individual projects based on conditions for licensing with little justification of need and with no provisions for later investigation to determine if the results were as anticipated or were justified by the costs.

Since 1980, hydropower regulatory actions have cost the country more than $\$ 7$ billion in license processing costs, mitigation costs, annual charges, and the value of lost power (assuming 30-year license terms). These actions have resulted in the loss of $1,170 \mathrm{MW}$ of hydroelectric capacity and 5.4 billion $\mathrm{kWHr} / \mathrm{Yr}$ of hydroelectric generation. In addition, these data foretell serious consequences in the future for the nation's hydropower resources under current law and regulation. The country can expect to endure $\$ 13.2$ billion in cost and lose at least $166 \mathrm{MW}$ of hydropower capacity and 5.3 billion $\mathrm{kWHrs} / \mathrm{Yr}$ of hydropower generation from the effects of conditions for upcoming relicensing actions. Thus, the total costs to the country for hydropower regulatory actions for the 30-year period $1980-2010$ is conservatively estimated to be $\$ 20.3$ billion (assuming 30-year license terms). This cost includes the loss of 1,334 MW of hydroelectric capacity and 10.7 billion $\mathrm{kWHrs} / \mathrm{Yr}$ of hydroelectric generation.

Finally, the report: (1) presents recent estimates that show $35,000 \mathrm{MW}$ of U.S. hydroelectric potential is untapped, even after eliminating sites unable to meet recent environmental and technical criteria; and (2) suggests items for possible further research that may help resolve some of the more serious impediments to hydropower development. 


\section{CONTENTS}

Section

HYDROPOWER IN THE U.S. ELECTRICITY MARKET

U.S. HYDROPOWER DEVELOPMENT

History of Hydropower Development

History of Hydropower Regulation

The Future of Hydropower

HYDROPOWER'S MARKET SHARE (1950-1995)

Renewables Market

Total Market

REGIONAL IMPACT OF HYDROPOWER -- 1996

2 THE STATUS OF HYDROPOWER DEVELOPMENT (1980-1996)

NEW LICENSES ISSUED

NEW PROJECTS PLACED IN SERVICE

NEW DAMS CONSTRUCTED FOR HYDROPOWER

$2-5$

RELICENSES ISSUED (1980-1996)

$2-6$

LICENSES SURRENDERED (1982-1996)

$2-6$

LICENSE APPLICATION PROCESSING TIME

$2-7$

REGULATORY EFFECTS ON HYDROPOWER RESOURCES (1980-1996) 3-1 CAPACITY AND GENERATION

Capacity

Relicensed Projects with Peaking Capacity Loss and Gain

Peaking Capacity Loss at Relicensing

Run-of-River Capacity Lost from Licenses Surrendered

Capacity Gain at Relicensing

Generation

Relicensed Projects with Generation Loss and Gain

Generation Loss at Relicensing

Generation Loss from Licenses Surrendered

3-10

Generation Gain at Relicensing

COSTS

License Processing Cost

Cost of Longer Processing Time after ECPA

Licensing and Study Costs by Project Size

License and Relicense Processing Costs (1980-1996)

3-16

Cost of Peaking Capacity Lost at Relicensing 
Cost of Lost Generation

At Relicensing

From License Surrenders

Other Mitigation Costs at Relicensing

Annual Charges

TOTAL COST OF HYDROPOWER REGULATION (1980-1996)

4 THE OUTLOOK FOR HYDROELECTRIC POWER

PROJECTS AT RISK

PROJECTED CAPACITY AND GENERATION LOSSES

4-1

PROJECTED VALUE OF CAPACITY AND GENERATION LOST

$4-2$

PROJECTED ADDITIONAL COSTS OF THE REGULATORY PROCESS

4-3

SUMMARY (1997-2010)

4-4

PROJECTED VALUE OF HYDROPOWER RESOURCE LOSSES (1980-2010) 4-4

ESTIMATED UNDEVELOPED U. S. HYDROPOWER POTENTIAL

4-5

IMPEDIMENTS AND ISSUES IN HYDROELECTRIC DEVELOPMENT

4-6

\section{Appendices}

A FEDERAL LAWS AFFECTING HYDROPOWER

B FOOTNOTES 


\section{ILLUSTRATIONS}

Figures

Figure

Page

1-1 Development of Conventional Hydropower Capacity in the U.S. (1920-1995) 1-1

1-2 Conventional Hydropower Generation in the U.S. (1920-1995)

1-3 Development of Pumped-Storage Hydropower

Capacity in the U.S. (1960-95)

1-4 Share of Renewable Energy Market - Installed Capacity (1975-1995)

Share of Renewable Energy Market -- Generation (1975-1995)

Share of U.S. Electricity Market -- Installed Capacity (1950-1995)

1-7 Share of U.S. Electricity Market - Generation (1950-1995)

2-1 New Licenses and Exemptions (1980-1996)

2-2 Non-Federal Projects Placed in Service (1980-1996)

2-3 Processing Time for Licenses and Exemptions (1980-1996)

2-4 Relicense Processing Time (1987-1996)

3-1 Projects Losing and Gaining Capacity at Relicensing 3-2

3-2 Peaking Projects Losing Capacity at Relicensing

3-3 Dependable Peaking Capacity Lost at Relicensing

3-4

3-4 Capacity Lost due to Licenses Surrendered

3-5

3-5 Average Capacity Gain Per Project Before and After ECPA

$3-6$

3-6 Projects Losing and Gaining Generation at Relicensing

3-8

3-7 Percent Generation Loss Before and After ECPA

$3-9$

3-8 Generation Loss from Surrendered Licenses

3-10

3-9 Generation Gain at Relicensing

3-12

3-10 Trends in Average Costs to Obtain a License

3-14

3-11 Range of Licensing Cost by Project Size

3-15

3-12

Average Licensing Expenditures for Studies

3-16

3-13 30-Year Mitigation Costs by Project Size 


\section{Tables}

Table

1-1 Installed Generating Capacity by Renewable Resource (Megawatts)

1.2 Generation by Renewable Resource (Million kWHrs//r)

1-3 Installed Generating Capacity by Resource (Megawatts)

1-4 Generation by Resource - U.S. (Billion kWHrs/Yr)

1-5 Conventional Hydropower of the United States - 1996

1-6 Regional Distribution of Conventional Hydropower

$$
\text { of the United States - } 1996
$$

2-1 New Licenses and Exemptions (1980-1996)

2-2 New Hydro Projects Placed in Service (1980-1996)

2-3 New Capacity Installed at Operating Projects (1980-1996)

2-4 New Projects Placed in Service - Status of Dams (1980-96)

2-5 Relicenses Issued (1980-1996)

2-6 Licenses Surrendered (1980-1996)

3-1 Summary of Regulatory Effects on Hydropower Capacity

3-2 Summary of Regulatory Effects on Hydropower Generation

4-1 Relicense Applications Pending and Licenses Expiring (1997-2010)

4-2 Projected Energy and Capacity Losses (1997-2010)

4-3 30-Year Costs for Pending Relicenses and Licenses Expiring (1997-2010)

4-4 Summary of Historical and Projected Generation and Capacity

Losses from Regulatory Actions (1980-2010)

4-5 30-Year Costs for the Historical and Projected Costs of Regulatory Actions 


\section{Section 1 \\ HYDROPOWER IN THE U. S. ELECTRICITY MARKET ${ }^{1}$}

\section{U.S. HYDROPOWER DEVELOPMENT}

\section{History of Hydropower Development}

Machinery driven by water may be the oldest and simplest technology for the production of energy on a large scale. What began as a mechanical means to power the early manufacturing plants became a source of electricity. U.S. hydropower turbines began producing their first electricity as early as 1880 and, by 1920 , hydropower facilities were generating nearly 20 billion kilowatt hours of electricity per year from $4,800 \mathrm{MW}$ of operating capacity.

Early hydropower was primarily owned and operated by town and city utilities, cooperatives, and manufacturers. Federal development of hydropower began around 1930 and grew steadily from 1930 to 1970 . By 1980 the operating capacity of federal facilities was about the same as that of non-federal installations and has remained about the same. Since 1980, the growth in all hydropower has been more gradual. Figures 1-1 and 1-2 show these trends.

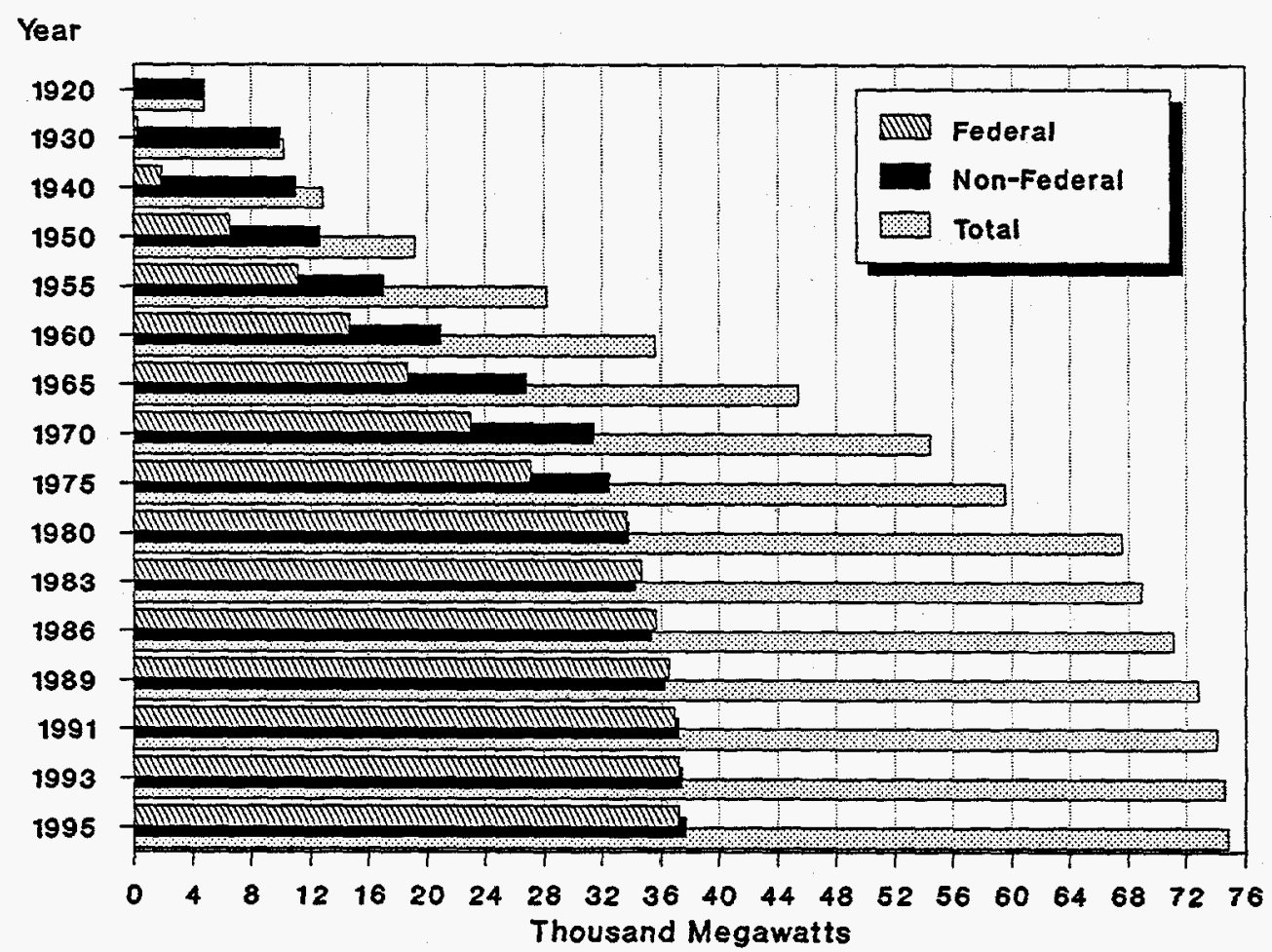

Figure 1-1. Development of Conventional Hydropower Capacity in the U. S. $(1920-1995)^{2}$ 


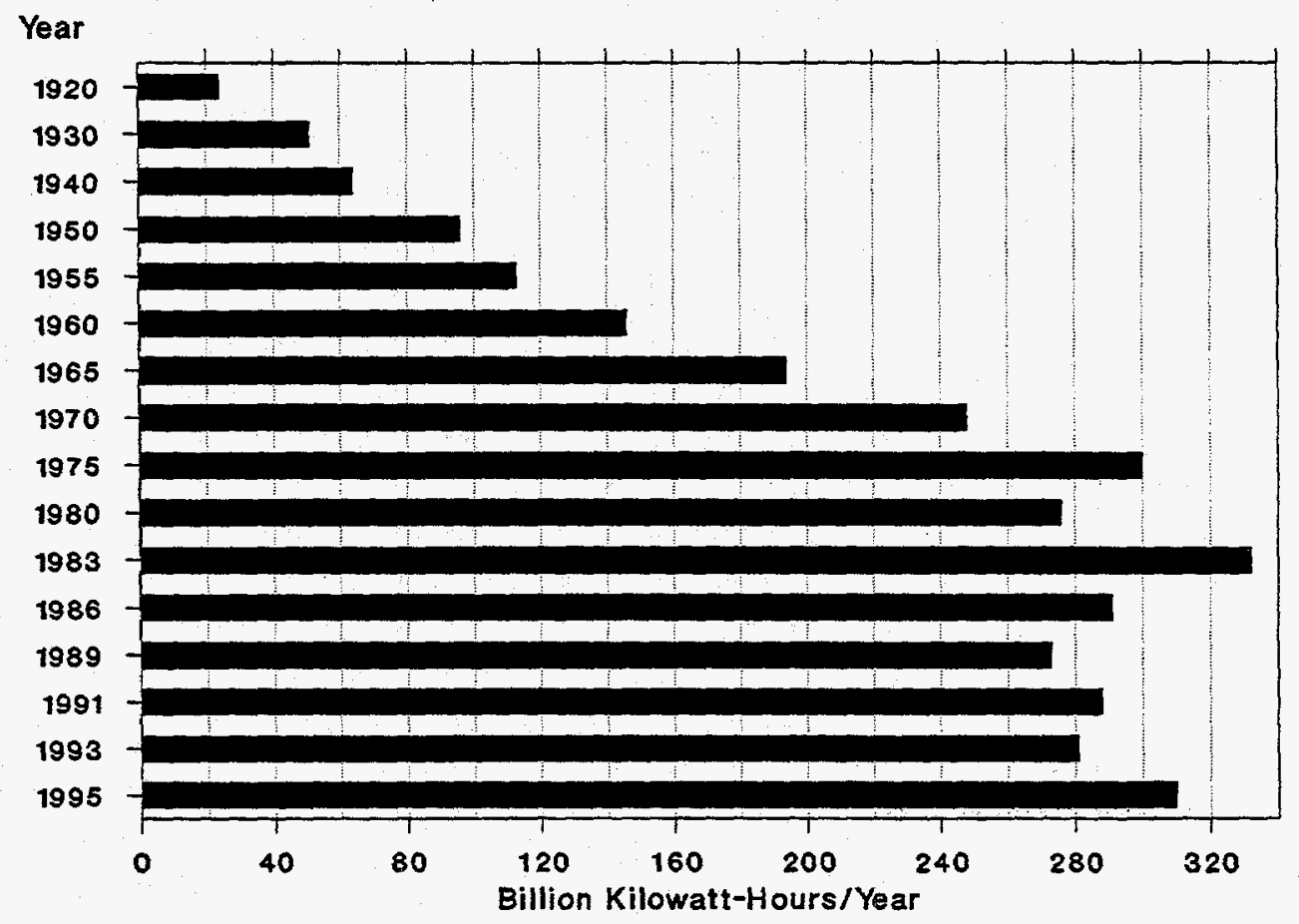

Figure 1-2. Conventional Hydropower Generation in the U. S. (1920-1995) ${ }^{3}$

There are two types of conventional hydropower, impoundment and diversion. An impoundment facility uses a dam to store water that can be released either to meet changing electricity needs or to maintain a constant reservoir level. A diversion facility uses a canal or penstock to channel a portion of the river flow to the hydropower plant. This type of installation may or may not require a dam. The amount of electricity produced is directly related to the volume of water directed through the turbines and the distance of water fall (or head).

Pumped-storage technology uses the water differently and satisfies a different purpose. A pumped-storage facility pumps water from a lower reservoir to an upper reservoir at times when there is low demand for electricity and excess electricity from fossil or nuclear base-load plants is available. When electricity demand is high, the water is released back to the lower reservoir to generate electricity. Pumped-storage plants can be closed systems that make no continuing demands on a river.

In 1929, a small $7 \mathrm{MW}$ pumped-storage project was built to test the value of this technology. Serious pumped-storage development began in 1960, but the technology made little contribution until 1970. Figure 1-3 shows the development trend for pumped-storage. 


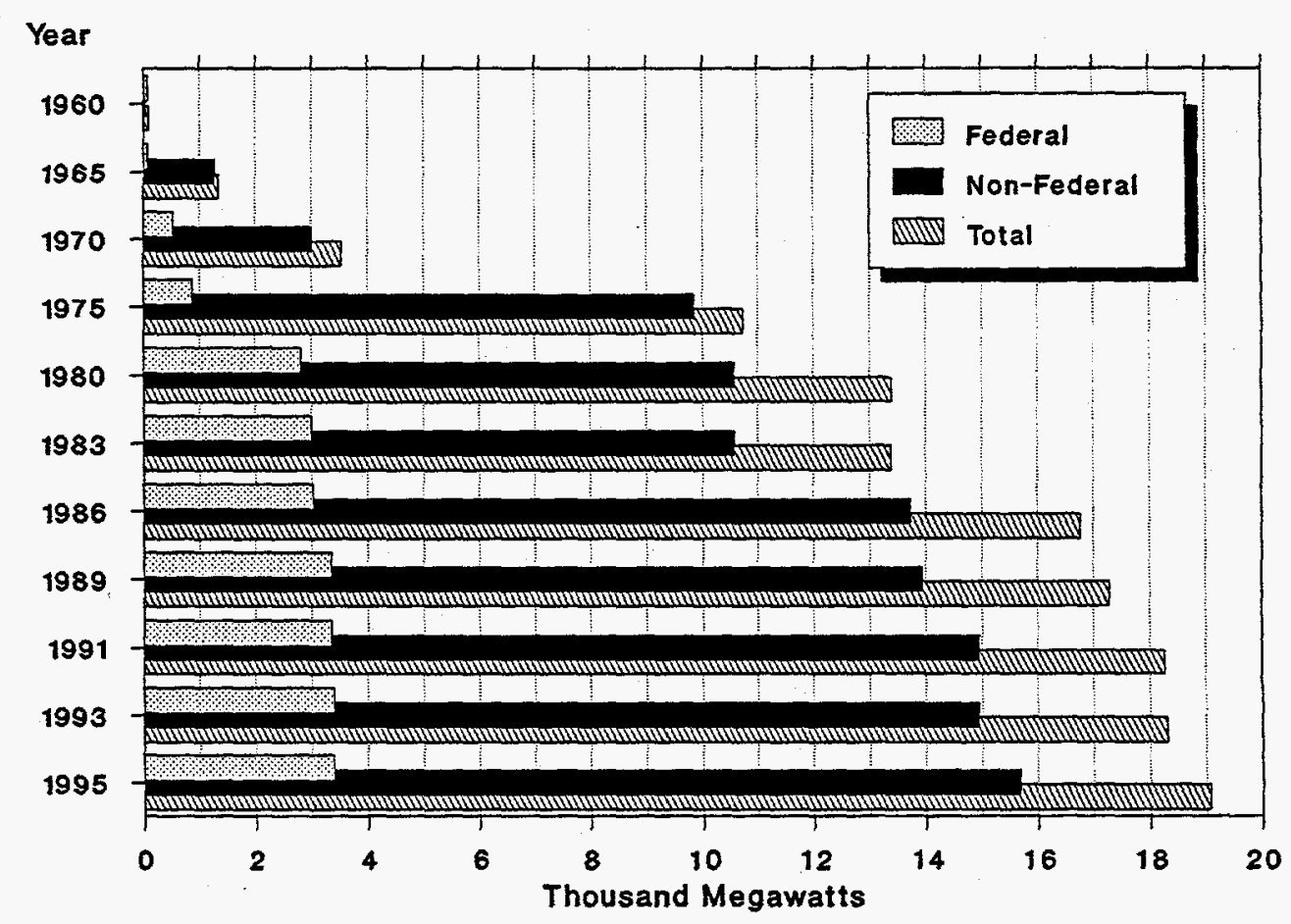

Figure 1-3. Development of Pumped-Storage Hydropower Capacity in the U. S. (1960-1995) ${ }^{4}$

The oil embargo of 1973 focused national attention on our energy vulnerability. Between 1973 and the late 1980's, there was increased interest in small scale hydropower development due to new legislation such as the Public Utility Regulatory Policies Act of 1978, the Energy Tax Act of 1978, the Crude Oil Windfall Profits Tax Act of 1980, the Energy Security Act of 1980, and the Economic Recovery Act of 1981. These laws offered economic incentives, removed obstacles to the development of small hydropower facilities, and provided a market for the power generated by such developments. The intent was to streamline the approval process for small projects in a way that would be more appropriate to their size and effect on the environment. While these incentives did result in the development of projects at many small sites from 1980 to 1996, the total growth in overall non-federal hydropower capacity gained during this period was less than $4,000 \mathrm{MW}$.

Nevertheless, the increased development activity raised environmental concerns and, as a result, the Electric Consumers Protection Act of 1986 (ECPA) included provisions whose implementation resulted in a longer and more confused hydropower licensing process. Consequently, the FERC's authority to direct this process is increasingly fragmented. Thus, the end result of national efforts to improve the hydropower approval process to encourage development of additional renewable hydropower resources is a process that has produced a net loss of the established generation base each year as operating plants renew their FERC licenses. 


\section{History of Hydropower Regulation}

Federal regulation of the nation's harbors and rivers began at the turn of the century with the Rivers and Harbors Act of 1899. This legislation recognized that rivers and streams flow across state lines and through various jurisdictions and that the construction of dams would affect the amount of water available for downstream populations. During this period, non-federal hydropower facilities were issued permits by the U.S. Secretary of War, whose department had considerable engineering and construction expertise. Under this permit system, the Department of War continued its limited hydropower regulating responsibility until the passage of the Federal Water Power Act of 1920 (FWPA).

The FWPA established the Federal Power Commission (FPC) and authorized it "to license certain hydroelectric projects that are best adapted to the comprehensive development of a waterway." The FWPA's successor, the Federal Power Act of 1935 (FPA), continues to the present time as the basis for the regulation of non-federal hydropower projects by the FPC's successor, the Federal Energy Regulatory Commission (FERC). The Federal Power Act gives the FERC jurisdiction over projects that are located on navigable waterways of the U. S., involve interstate commerce, or involve construction after 1935. The FPA directed FERC to issue hydropower licenses to such projects for a period not exceeding 50 years.

The Public Utility Regulatory Policies Act of 1978 (PURPA) was enacted to encourage clean, renewable sources of energy by providing incentives and removing regulatory obstacles to the development of such projects. PURPA clearly established small-scale hydropower as a source of renewable energy so that hydropower enjoyed all the benefits of this law including tax credits, accelerated depreciation allowances, and exemption from licensing for small projects meeting certain conditions.

The Electric Consumers Protection Act of 1986 (ECPA) specifically required the FERC to balance all uses involved in the development of a hydropower project "in the public interest." In addition to considering the development of the electrical generation, the FERC must give "equal consideration" to energy conservation, the protection and enhancement of fish and wildlife resources (including related spawning grounds and habitat), the protection of recreational opportunities, and the preservation of all other aspects of environmental quality. These other aspects can include navigation, irrigation, aesthetics, water quality, and cultural or historical sites. However, some uses have enjoyed higher priority. For example, to reject a fish and wildlife recommendation, the FERC must show an inconsistency of this recommendation with the law or other interests that must be balanced in the licensing process. 
PURPA and ECPA have had the most direct influence on the development of new hydropower resources. However, more than $\mathbf{4 0}$ other federal laws must also be considered by the FERC before approving a hydropower license. Except for nuclear, no other generating source faces such a burdensome licensing procedure. The effects of these laws on the hydropower industry are evident in the data reported below.

\section{The Future of Hydropower}

The data and trends reported in the next pages show hydropower's current situation, including the increase in licensing costs, the loss of power in recent years, and the dramatic increase in mitigation costs. This report also predicts the probable effect of these recent trends on the large projects that will be at risk in the relicensing process during the next 15 years.

\section{HYDROPOWER'S MARKET SHARE (1950-1995)}

\section{Renewables Market}

The Energy Information Administration (EIA) of the Department of Energy defines a renewable energy resource as follows: "An energy source that is regenerative or virtually inexhaustable. Typical examples are wind, geothermal, and water power." EIA renewables data also include the burning of wood and waste, "fuels" which are presumably inexhaustable.

In the 20-year period 1955-1975, hydropower accounted for more than 99 percent of the renewable energy market. Figures 1-4 and 1-5 show the percent share of the renewables market for the installed capacity and generation, respectively, for each renewable resource from 1975 through 1995. As recently as 1986, hydropower's share of the renewables market for both capacity and generation exceeded 96 percent. After 1986, hydropower's share declined to 82 percent of total renewable capacity and 79 percent of total renewable generation. The technology displacing hydropower's loss of market share is burning wood and waste. Also, in 1995, wind and solar provided a combined 2.5 percent of total U.S. renewable capacity and less than 1.5 percent of total U.S. renewable generation. 
Year (\% Hydro)

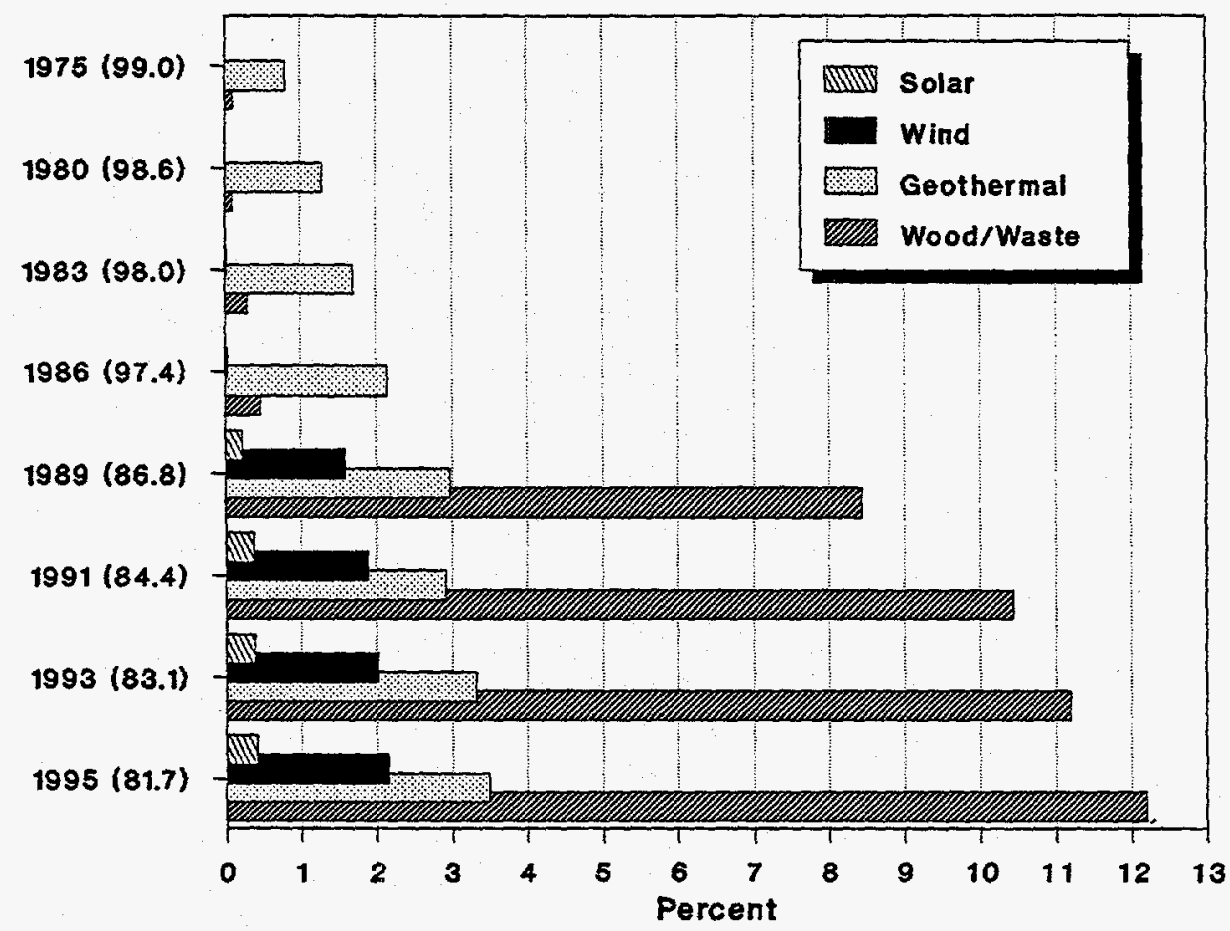

Figure 1-4. Share of Renewable Energy Market -Installed Capacity (1975-1995)

Year (\% Hydro)

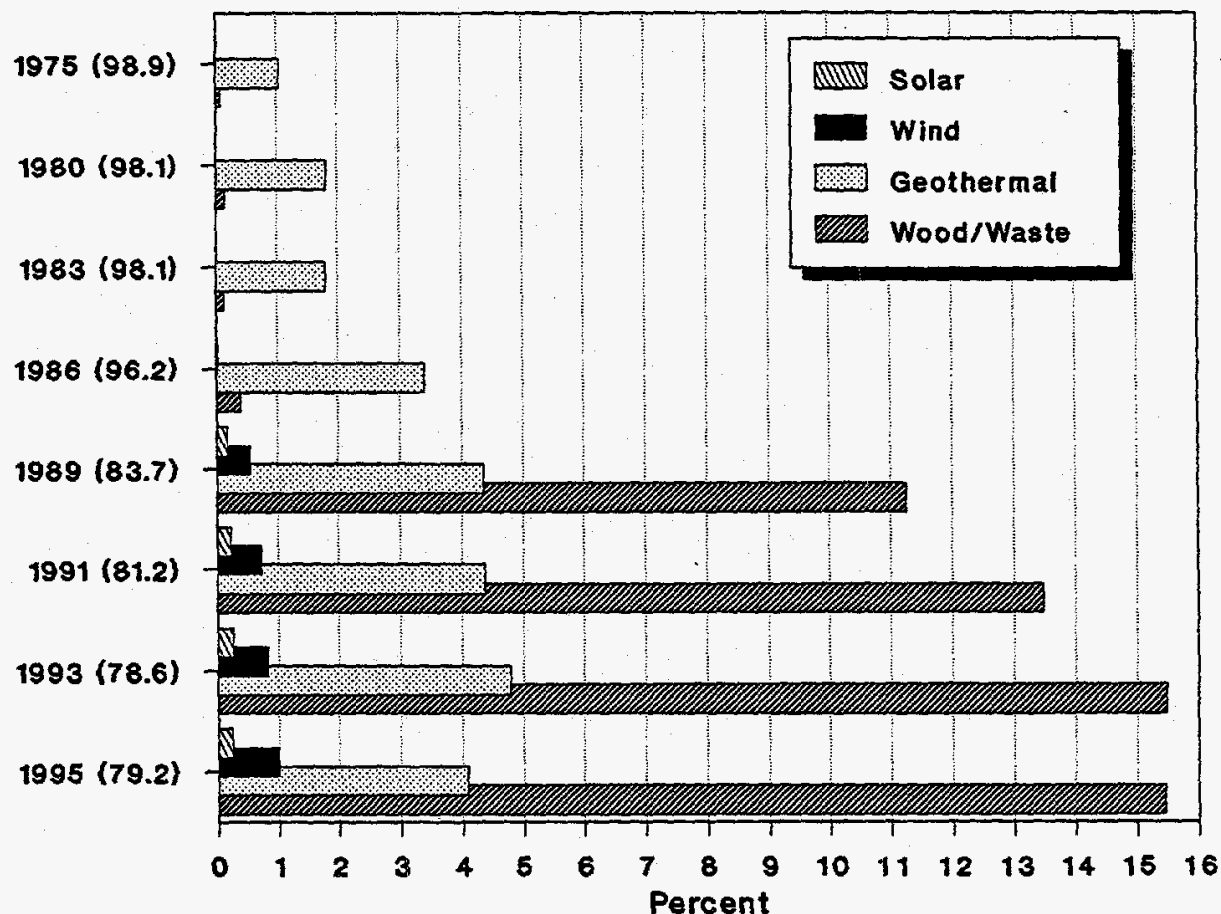

Figure 1-5. Share of Renewable Energy Market -Generation (1975-1995) ${ }^{6}$ 
Table 1-1

Installed Generating Capacity By Renewable Resource

(Megawatts)

\begin{tabular}{|c|c|c|c|c|c|c|c|c|}
\hline Resource & 1955 & 1975 & 1983 & 1986 & 1989 & 1991 & 1993 & 1995 \\
\hline Conv. Hydro ${ }^{2}$ & 28,205 & 59,515 & 68,935 & 71,075 & 72,800 & 74,055 & 74,605 & 74,875 \\
\hline Wood Waste $^{7}$ & 35 & 80 & 210 & 340 & 7,070 & 9,130 & 10,045 & 11,170 \\
\hline Geothermal $^{7}$ & 0 & 500 & 1,210 & 1,560 & 2,490 & 2,550 & 2,980 & 3,195 \\
\hline Wind $^{7}$ & 0 & 0 & 5 & 20 & 1,340 & 1,655 & 1,810 & 1,975 \\
\hline Solar ${ }^{7}$ & 0 & 0 & 0 & 0 & 185 & 320 & 340 & 375 \\
\hline TOTALU.S. & 28,240 & 60,095 & 70,360 & 72,995 & 83,885 & 87,710 & 89,780 & 91,590 \\
\hline
\end{tabular}

Table 1-2

Generation By Renewable Resource

(Million kWHrs/Yr)

\begin{tabular}{|c|c|c|c|c|c|c|c|c|}
\hline Resource & 1955 & 1975 & 1983 & 1986 & 1989 & 1991 & 1993 & 1995 \\
\hline Conv. Hydro 3 & 113,000 & 300,000 & 332,000 & 291,000 & 273,000 & 288,000 & 281,000 & 310,000 \\
\hline Wood/Waste ${ }^{8}$ & 280 & 200 & 400 & 1,200 & 36,700 & 47,800 & 55,300 & 60,500 \\
\hline Geothermal $^{8}$ & 0 & 3,200 & 6,100 & 10,300 & 14,200 & 15,500 & 17,100 & 16,000 \\
\hline Wind $^{8}$ & 0 & 0 & 3 & 20 & 1,800 & 2,600 & 3,000 & 3,900 \\
\hline Solar ${ }^{8}$ & 0 & 0 & 0 & 0 & 500 & 800 & 900 & 900 \\
\hline TOTALS & 113,280 & 303,400 & 338,503 & 302,520 & 326,200 & 354,700 & 357,300 & 391,300 \\
\hline
\end{tabular}


Hydropower represents a significant share of the nation's electric power market. Figures 1-6 and 1-7 show the percent share of the U.S. electricity market in percent for fossil, nuclear, hydropower, and other renewables' installed capacity and generation, respectively, from 1950 through 1995.

In the 25 year period 1950-1975, hydropower's share of the country's generating capacity declined from 28 percent to 12 percent. During that same period, hydropower's share of U.S. electricity generation declined from 29 percent to 15.5 percent. During the next few years hydropower experienced smaller declines, settling at about 10 percent of the capacity market and 9 percent of the generation market. Since 1975, pumped-storage hydropower has contributed an additional 2 percent of the nation's total installed generating capacity. Since 1989, there has been little change in hydropower's market share. The small fluctuations in annual generation are most likely attributable to variations in rainfall and river flow around the country from year to year.

A comparison of the "Conv. Hydro" rows on Tables 1-3 and 1-4 reveals that conventional hydropower capacity increased by 25 percent between 1975 and 1995, but that conventional hydropower generation remained nearly the same. This indicates that hydropower is being used less efficiently today than it was 20 years ago. Either hydropower operators are voluntarily sacrificing efficiency and generation, or regulatory conditions placed on hydropower facilities in the past 20 years are substantially reducing potential output.

In 1995, fossil plants produced more than 68 percent of U.S. electricity with about 73 percent of the nation's installed capacity. This market share for fossil plants was about the same as in 1950. 


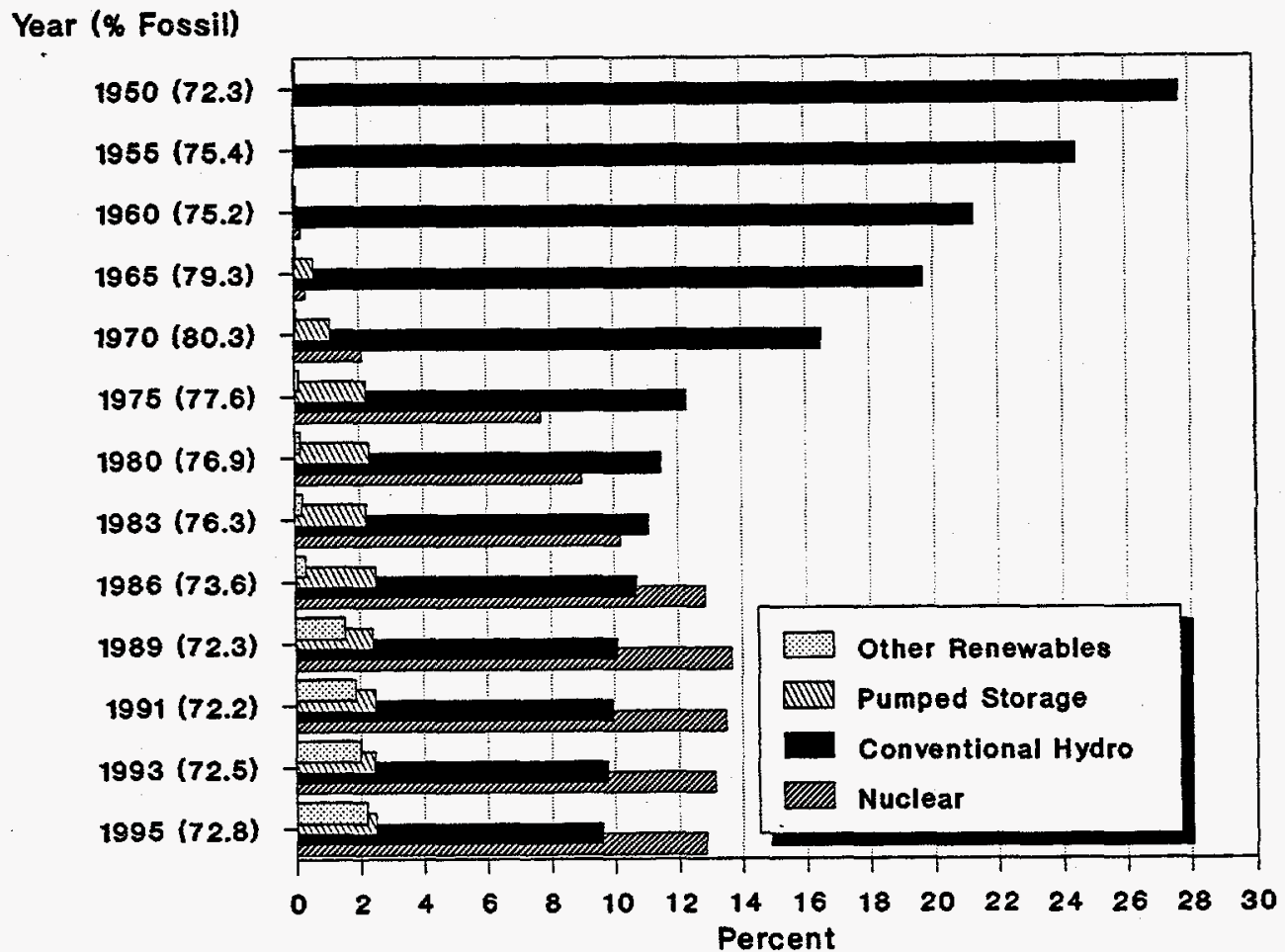

Figure 1-6. Share of U. S. Electricity Market Installed Capacity (1950-1995) ${ }^{9}$

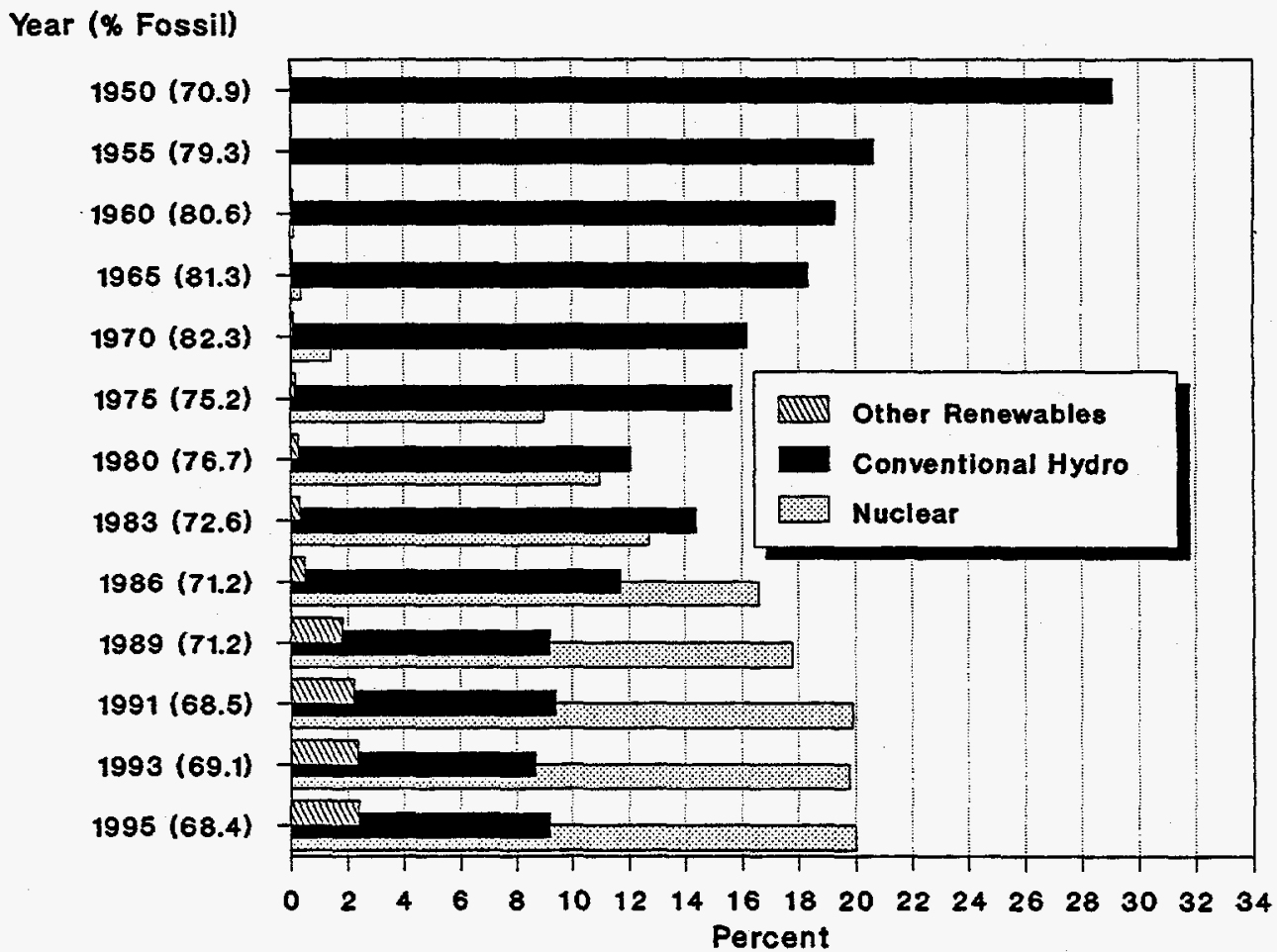

Figure 1-7. Share of U.S. Electricity Market Generation (1950-1995) ${ }^{10}$ 
Table 1-3

Installed Generating Capacity By Resource (Megawatts)

\begin{tabular}{|c|c|c|c|c|c|c|c|c|}
\hline Resource & 1955 & 1975 & 1983 & 1986 & 1989 & 1991 & 1993 & 1995 \\
\hline Fossill 11 & 86,900 & 375,200 & 472,900 & 488,600 & 520,500 & 534,400 & 547,100 & 562,100 \\
\hline Conventional Hydro ${ }^{2}$ & 28,205 & 59,515 & 68,935 & 71,075 & 72,800 & 74,055 & 74,605 & 74,875 \\
\hline Nuclear $^{12}$ & 0 & 37,300 & 63,000 & 85,200 & 98,200 & 99,600 & 99,000 & 99,100 \\
\hline P-S Hydro ${ }^{4}$ & 25 & 10,720 & 13,585 & 16,770 & 17,275 & 18,275 & 18,315 & 19,075 \\
\hline Other Renewables $^{13}$ & 35 & 580 & 1,425 & 1,920 & 11,085 & 13,655 & 15,175 & 16,715 \\
\hline TOTALS & 115,165 & 483,315 & 619,845 & 663,565 & 719,860 & 739,985 & 754,195 & 771,865 \\
\hline
\end{tabular}

Table 1-4

Generation By Resource

(Billion kWHrs/Yr)

\begin{tabular}{|c|c|c|c|c|c|c|c|c|}
\hline Resource & 1955 & 1975 & 1983 & 1986 & 1989 & 1991 & 1993 & 1995 \\
\hline Fossil $^{14}$ & 433 & 1,442 & 1,677 & 1,772 & 2,118 & 2,109 & 2,239 & 2,302 \\
\hline Conventional Hydro ${ }^{3}$ & 113 & 300 & 332 & 291 & 273 & 288 & 281 & 310 \\
\hline Nuclear ${ }^{15}$ & 0 & 173 & 294 & 414 & 529 & 613 & 640 & 673 \\
\hline Other Renewables ${ }^{16}$ & -.. & 3 & 7 & 12 & 53 & 67 & 76 & 81 \\
\hline TOTALS & 546 & 1,918 & 2,310 & 2,489 & 2,973 & 3,077 & 3,236 & 3,366 \\
\hline
\end{tabular}


Table 1-5 shows the number of operating conventional hydroelectric plants in the United States, their installed capacity, and their average annual generation. The FERC licenses 79 percent of the nation's hydropower facilities, including about half of the nation's hydropower capacity and generation. By comparison, there are far fewer federally-owned facilities, only 7 percent of the U.S. hydropower plants, but they contain nearly half of the country's installed hydropower capacity and deliver almost 40 percent of its electricity. With the exception of those operated by the Tennessee Valley Authority, these very large federal hydropower plants are concentrated in the western United States. Unlicensed facilities are generally older, "grandfathered" facilities or those that are not on navigable waterways.

Table 1-5

Conventional Hydropower of the United States - $1996^{17}$

\begin{tabular}{|c|c|c|c|}
\hline Category & $\begin{array}{l}\text { Operating } \\
\text { Plants }\end{array}$ & $\begin{array}{c}\text { Installed } \\
\text { Capacity } \\
\text { (MW) }\end{array}$ & $\begin{array}{l}\text { Average Annual } \\
\text { Generation } \\
\text { (Billion kWHrs } / \text { r) }\end{array}$ \\
\hline Federal & 172 & 37,289 & 145 \\
\hline FERC-Licensed & 1,890 & 35,908 & 161 \\
\hline Unlicensed & 336 & 1,876 & 8 \\
\hline TOTALS & 2,398 & 75,073 & 314 \\
\hline
\end{tabular}

Table 1-6 shows the distribution of hydropower plants, their capacity, and their average annual generation for areas roughly equivalent to the North American Electric Reliability Council regions for the contiguous United States and Alaska. With only 16 percent of U.S. plants and about 45 percent of the nation's hydropower capacity, the five states that make up the northwest region produce almost half of all U.S. hydroelectric power. One quarter of the nation's plants and about 19 percent of the available capacity are in the far western states. These plants produce 17.5 percent of U.S. hydropower output. By contrast, the six New England states, with 19 percent of the country's hydropower plants, have only 2.5 percent of U. S. hydro generating capacity and produce only 2.5 percent of the nation's hydroelectric power. 
Table 1-6

Regional Distribution of Conventional Hydropower of the United States - $1996^{17}$

Region

New England

(ME,NH,VT,MA,RI,CT)

New York

Middle Atlantic

(NJ,PA,DE,MD)

Southeast

(NA,NC,TN,SC,GA,AL,MS,FL)

Midwest

$(\mathrm{WW}, \mathrm{OH}, \mathrm{KY}, \mathrm{IN}, \mathrm{MI}, \mathrm{IL}, \mathrm{WI})$

Northern Plains

(MN,ND,SD,IA,NE)

Central Plains

(KS,MO,OK,AR,LA)

Texas

Northwest

(MT,WY,ID,WA,OR)

Far West

(CO,UT,NV,CA,AZ,NM)

Alaska

TOTALS
Installed

Capacity

(MW)

1,978

4,293

1,280

11,086

2,240

2,896

65

33

28

393

570

39

416

2,398
11.7

1.7

Average Annual

Generation

(Billion kWHrs/Yr)

7.9

25.3

4.3

33.7

12.7

11.7

1.7

153.4

54.9

314.0 


\section{Section 2 \\ THE STATUS OF HYDROPOWER DEVELOPMENT $(1980-1996)^{18}$}

Between 1980 and 1996, the Federal Energy Regulatory Commission issued new orders for 1,457 major and minor licenses, exemptions, and conduit exemptions for hydropower development. A major license application must be filed for project sites with a total generating capacity greater than $1.5 \mathrm{MW}$. A minor application may be filed for projects of $1.5 \mathrm{MW}$ or less. In 1980, the exemption category was established for projects with negligible environmental impact. Under this category, a project can be exempted from certain licensing requirements of the Federal Power Act. Such projects would be installed at existing dams where the reservoir could be maintained at a stable, pre-development level and are limited to capacities of $5 \mathrm{MW}$ or less. Since the enactment of ECPA, certain municipal projects up to $40 \mathrm{MW}$ in capacity may also qualify for exemptions.

Exemptions do not expire nor do their owners pay annual charges to the FERC. However, beginning in 1984, obtaining an exemption involved greater risk. At that time, the FERC gave resource agencies (such as the U. S. Fish and Wildlife Service, state fish and game departments, the National Marine Fisheries Service, the National Park Service, and the Forest Service) the authority to place mandatory conditions on all exemptions.

The conduit exemption is a special category of exemption. To qualify, a project must use a closed conduit system, such as a waste treatment plant discharge or irrigation system, to deliver water to the turbine. The water used to operate such a project must originate from a source other than natural river flow.

The Federal Power Act requires that all projects licensed by the FERC be "best adapted to plans for the comprehensive development of the river basin." Therefore, all licenses and exemptions issued by the FERC contain standard requirements that address the optimum development and balance of resources and the safety of project structures. Each license must also directly address the enhancements that the project will provide for recreational opportunities and fish and wildlife resources.

After 50 years of operation under an initial license, the licensee must apply for a relicense in order to continue operating the project. Within the framework of the Federal Power Act, the FERC analyzes how the continued operation of the project affects all of the above issues. Some changes in the historic operation of the project can be anticipated to satisfy today's environmental and social values. 


\section{NEW LICENSES ISSUED}

Figure 2-1 shows the number of new, non-federal major and minor licenses, exemptions, and conduit exemptions issued by the FERC each year from 1980 through 1996. During this period, 1,457 orders were issued. Most came during the pre-ECPA period from 1980 through 1986.

The number of new license orders peaked at 109 in 1986. Almost immediately after 1986, all major and minor license issuances began to decline. After 1989, the licensing activity fell off sharply until only 3 licenses were issued in 1996.

The decline in new exemptions issued by the FERC began earlier. From a peak of 161 exemption and conduit exemption issuances in 1983, only 26 exemptions have been issued since 1990.

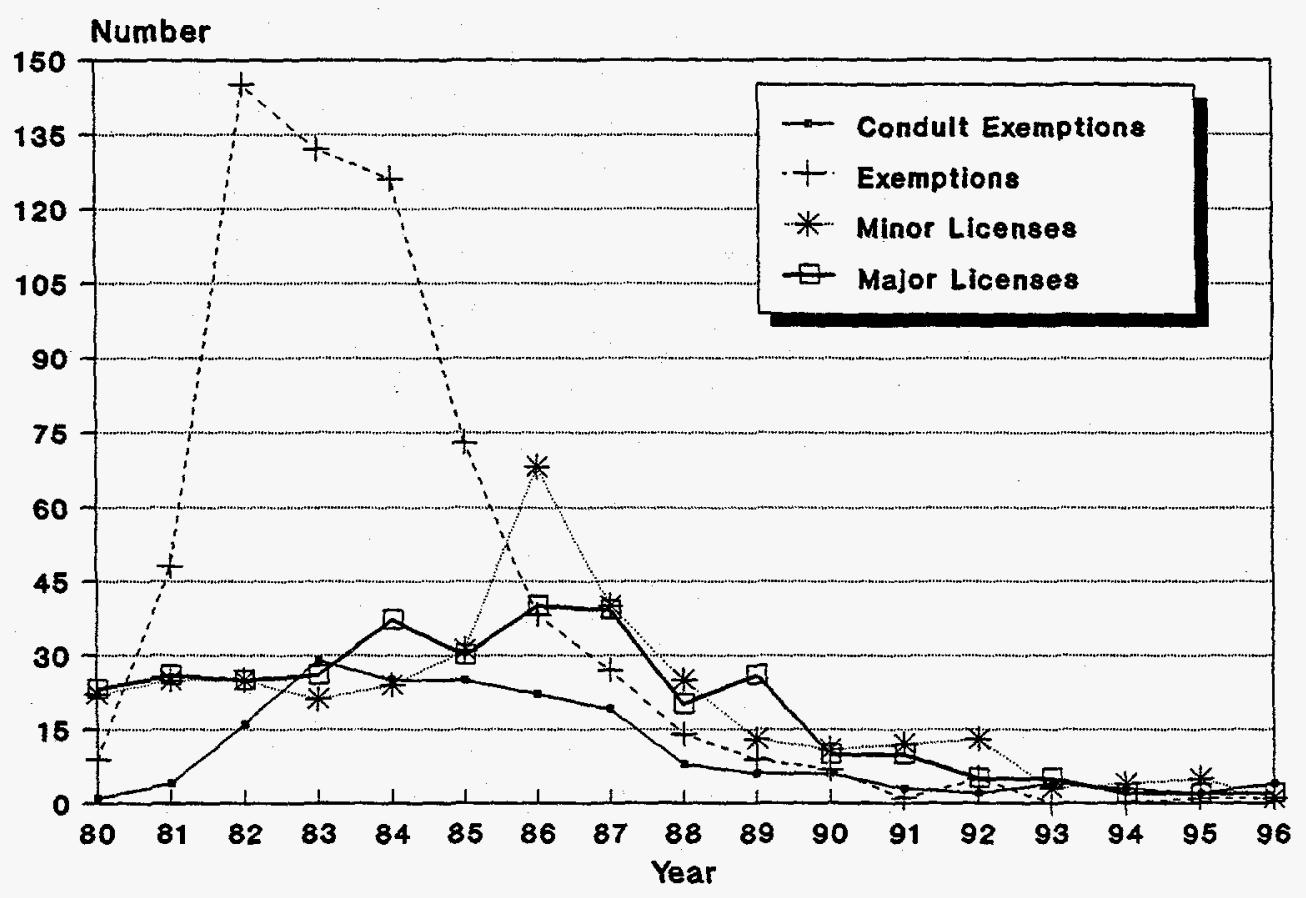

Figure 2-1. New Licenses and Exemptions (1980-1996)

Table 2-1 shows the number and capacity of the new hydropower licenses and exemptions issued by the FERC from 1980 through 1996. 
Table 2-1

New Licenses and Exemptions (1980-1996)

Pre-ECPA

(1980-86)

Projects

Capacity (MW)

2,540

1,086
Post-ECPA

(1987-96)

371

1,946

1,457

4,458

\section{NEW PROJECTS PLACED IN SERVICE}

Figure 2-2 shows the number of new, non-federal projects under FERC jurisdiction placed in service each year from 1980 through 1996. The number of new projects grew rapidly each year in response to incentives provided in laws such as the Energy Tax Act of 1978, the Energy Security Act of 1980, the Crude Oil Windfall Profits Act of 1980, and the Economic Recovery Act of 1981. This rapid growth peaked in 1985.

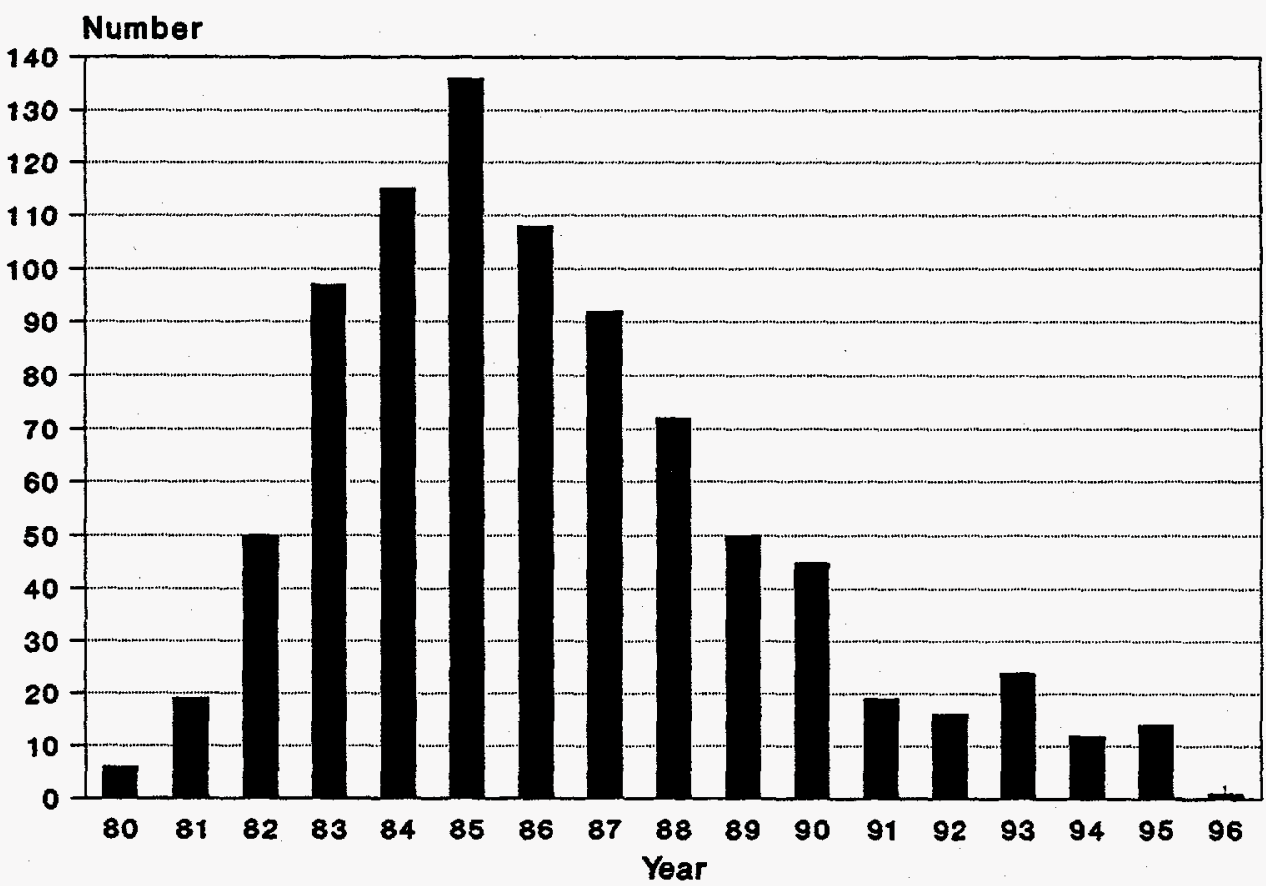

Figure 2-2. Non-Federal Projects Placed In Service (1980-1996) 
With the expiration of PURPA incentives and the implementation of ECPA, the number of projects placed in service each year began to decline until, in 1996, only one $0.4 \mathrm{MW}$ project began operation. The larger projects with license applications already in progress at the time of ECPA continued in the process. Because these large projects take longer to process, they continued to come on line. Therefore, new capacity in service remained stable until 1993 even as the number of projects declined overall.

Table 2-2 shows the number and capacity of new, non-federal projects under FERC jurisdiction placed in service from 1980 through 1996. Table 2-3 shows the amount of new capacity installed at already operating projects during the period.

Table 2-2

New Hydro Projects Placed In Service (1980-1996)

Pre-ECPA

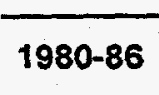

531

Projects

Capacity (MW)

1,782
Post-ECPA

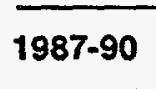

259

1,546
Post-ECPA

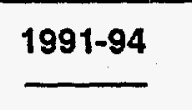

71

528

$1995 \quad 1996$

14

76.6

\section{TOTALS}

1980-96

876

3,933

Table 2-3

New Capacity Installed at Operating Projects (1980-1996)

\begin{tabular}{|c|c|c|c|c|c|c|}
\hline & \multirow{2}{*}{$\frac{\text { Pre-ECPA }}{1980-86}$} & \multicolumn{4}{|c|}{ Post-ECPA } & \multirow{2}{*}{$\frac{\text { TOTALS }}{1980-96}$} \\
\hline & & $1987-90$ & $1991-94$ & 1995 & 1996 & \\
\hline $\begin{array}{r}\text { New Capacity } \\
\text { Projects }\end{array}$ & 24 & 3 & 6 & - & - & 33 \\
\hline Capacity (MW) & 285 & 37 & 19 & - & - & 341 \\
\hline
\end{tabular}




\section{NEW DAMS CONSTRUCTED FOR HYDROPOWER}

Of the 876 new FERC-regulated projects placed in service since 1980, only 34 involved the construction of a new dam. Only 6 of these dams are more than 100 feet high; 4 of the 6 are located in Alaska and one (South Carolina) is for a combined conventional / pumped-storage project. The remaining 28 are 3 to 30 feet high.

Five hundred and fifteen (515) projects were developed at existing dams. Most of these dams were originally constructed as: impoundments for hydropower operation (and abandoned many years ago); lock facilities for navigation; or, water storage for irrigation, flood control, or water supply.

There were no dams involved in the development of the remaining 327 new projects. These projects typically use low diversion structures at the side of a stream, an irrigation conduit, or a sewage plant discharge conduit.

Table 2-4 shows the status of dam construction for projects placed in service since 1980.

Table 2-4

New Projects Placed In Service - Status of Dams (1980-96)

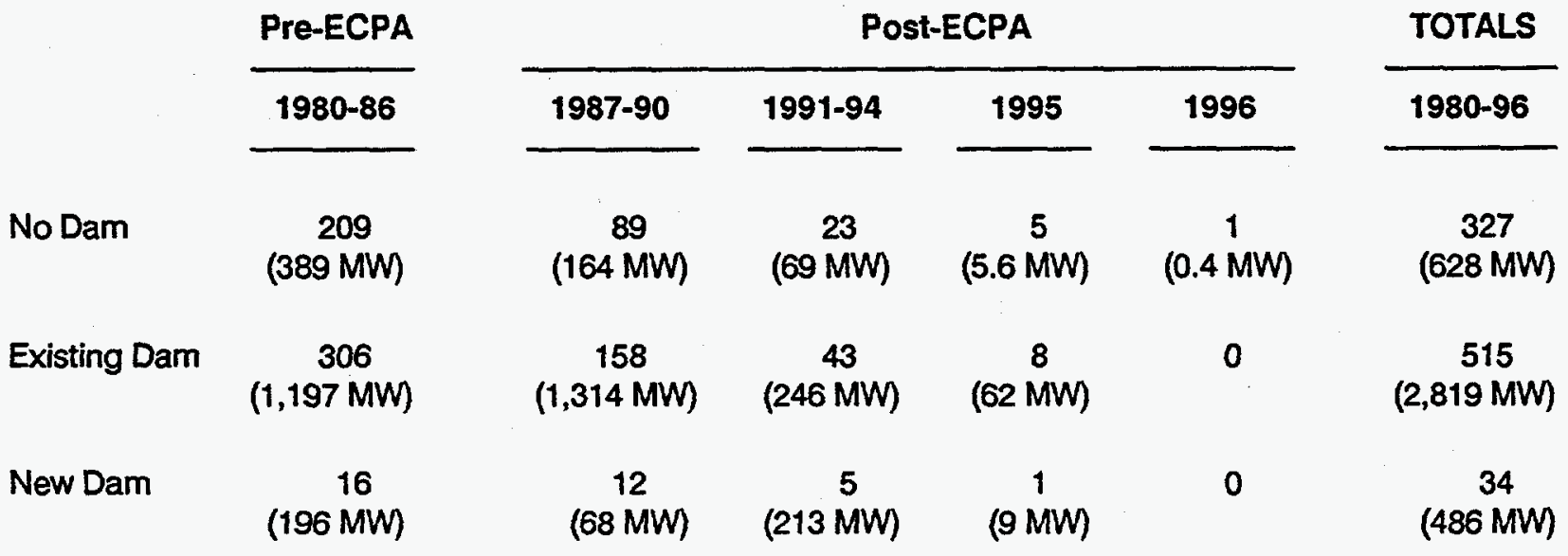


During the period 1980 through 1996, 163 relicenses were issued. Half of these were issued in the past 3 years. The experiences of these relicense applicants form the basis of our projections later in this report. Applicants found that the relicensing process was more burdensome and contentious, more studies were required of each applicant, more of the power resource was lost, and the licensing time required was longer than ever before.

In addition, these applicants did not receive permanent licenses where all of the requirements and operating conditions for the project were known for the term of the license, as they had in the past. More than half of the articles in relicenses issued since the enactment of ECPA are open-ended articles that allow agencies to reopen the license at any future time and mandate modifications in project structures or operation. $^{19}$

Table 2-5 shows the number and capacity of relicenses issued from 1980 through 1996.

Table 2-5

Relicenses Issued (1980-1996)

\begin{tabular}{|c|c|c|c|c|c|c|}
\hline & \multirow{2}{*}{$\frac{\text { Pre-ECPA }}{1980-86}$} & \multicolumn{4}{|c|}{ Post-ECPA } & TOTALS \\
\hline & & $1987-90$ & $1991-94$ & 1995 & 1996 & $1980-96$ \\
\hline Relicenses & 63 & 38 & 81 & 17 & 27 & 226 \\
\hline Capacity (MW) & 3,260 & 899 & 970 & 864 & 505 & 6,498 \\
\hline
\end{tabular}

\section{LICENSES SURRENDERED (1982-1996)}

In today's regulatory environment, hydropower licenses are surrendered in two events: 1) licenses are surrendered before a project is built, or 2) operating projects are deactivated and their licenses surrendered. Of the 1,457 new licenses and exemptions issued by the FERC between 1980 and 1996, 487 or more than 33 percent were ultimately surrendered before the projects were built. Another 16 licenses were surrendered for projects that were deactivated. Only one of these surrenders occurred prior to ECPA. Table 2-6 shows the number and total capacity of the licenses surrendered from 1980 through 1996. 
Table 2-6

Licenses Surrendered (1980-96)

Without

Developing

Deactivated

TOTALS

Projects

487

16

503

Capacity (MW)

1,057

13

1,070

\section{LICENSE APPLICATION PROCESSING TIME}

As shown in Figure 2-3, the length of time required to obtain a license varies by project size. Major licenses issued during the period 1994-1996 took more than 5 years to process; minor licenses took 3.5 years; exemptions took over a year and a half; and conduit exemptions took about a year. By comparison, a major or minor license would have been issued in about 9 months in 1980, and exemptions would have been processed in about 5 months.

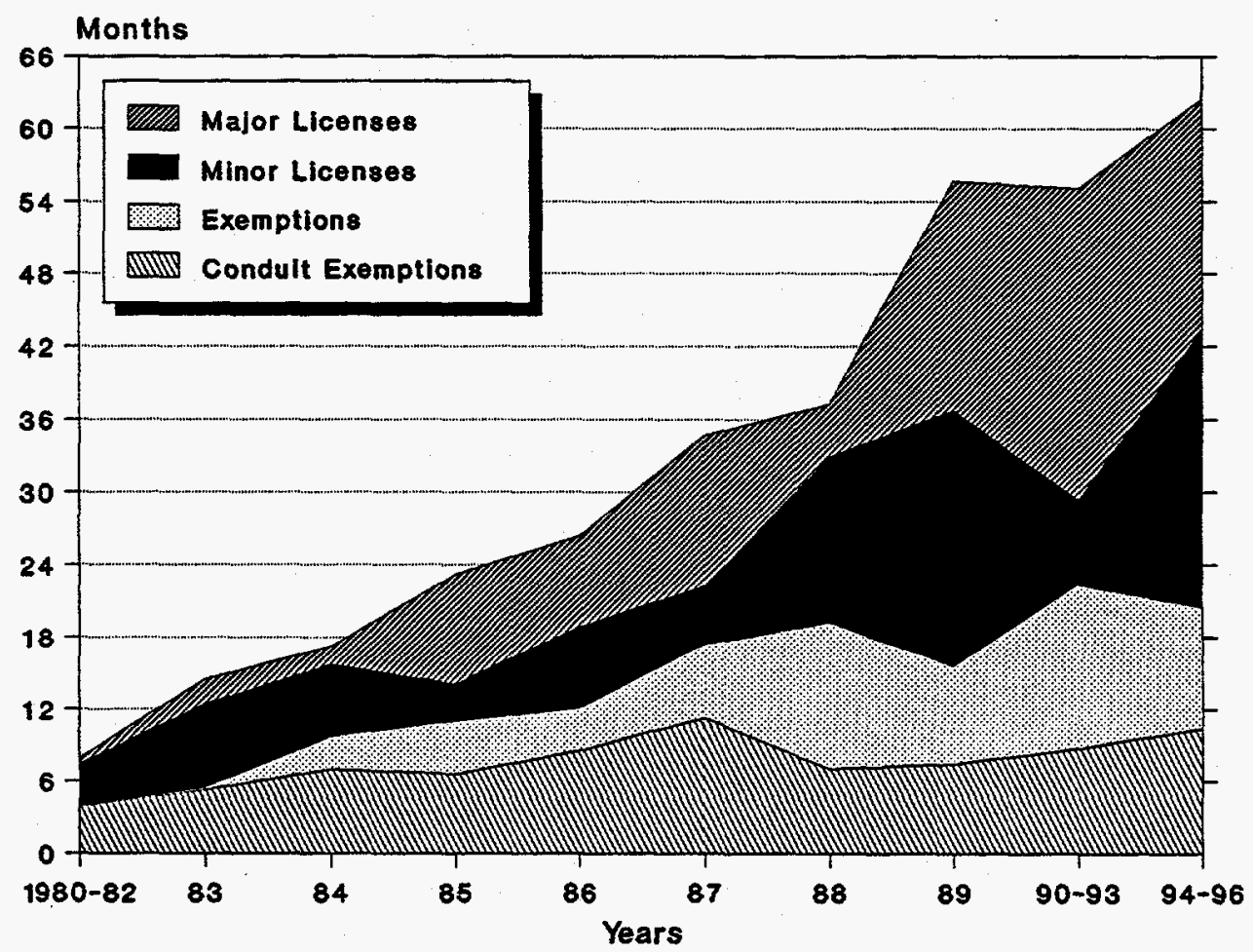

Figure 2-3. Processing Time for Licenses and Exemptions (1980-1996) 
Figure 2-4 shows that the processing time has also increased for relicenses. Applicants who received relicenses during the period 1994-1996 spent about 4.5 years in the regulatory process. By contrast, relicenses issued in 1987 were processed in less than 3 years.

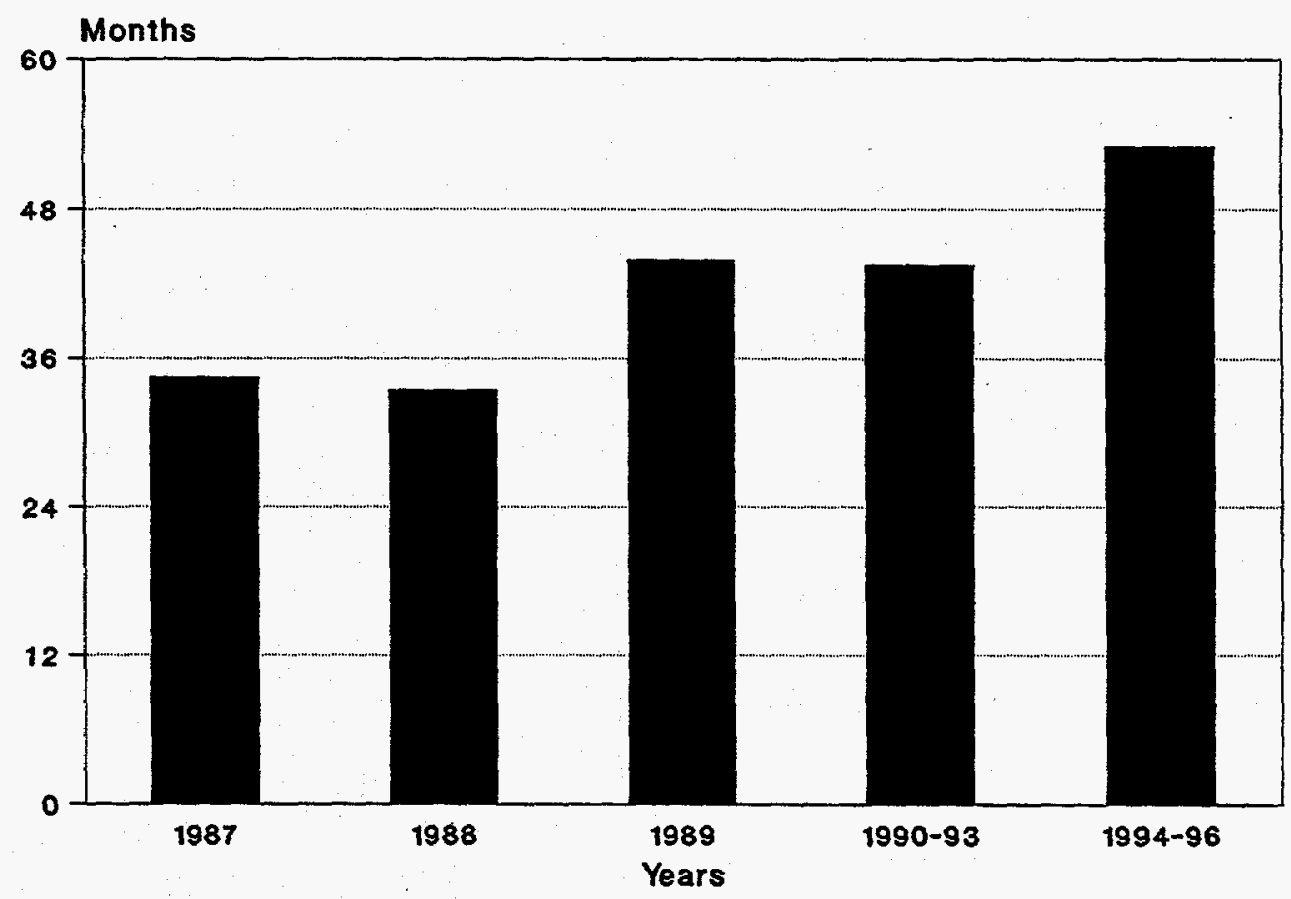

Figure 2.4. Relicense Processing Time (1987-1996) 


\section{Section 3 \\ REGULATORY EFFECTS ON HYDROPOWER RESOURCES (1980-1996)}

Hydropower resources are at risk in today's regulatory environment. This is evident by the number of hydropower licenses surrendered, both for operating projects and projects never built, and the loss of capacity and generation at most projects relicensed in recent years.

In addition to the documented loss of power, trend data on relicensing actions since 1986 show the increased cost of relicensing and reduced economic viability of individual projects. Nationally, the total effect of hydropower relicensing since 1986 has been a reduced market share for hydropower along with a general reduction in the economic viability of this renewable resource.

\section{CAPACITY AND GENERATION}

The committee conference report for ECPA indicated Congress' intent and expectation that older hydropower projects would not be decommissioned as a result of ECPA. Rather, older projects would be changed to reflect today's social and environmental values while preserving their economic viability.

Relicensing should also afford an opportunity to increase the output and efficiency of older projects. When the projects now undergoing relicensing were initially developed more than 50 years ago, many were sized to meet specific energy needs and not for the full potential of the site. Therefore, undeveloped hydro potential should be available at these sites. ${ }^{20}$ In addition, improvements in turbine technology should allow an increase in capacity and generation at relicensing, given the same operating conditions of the original license.

Instead, the experiences of projects relicensed since ECPA demonstrate that there is an increased risk of losing generation in the relicense. And there is a substantial continuing risk of losing hydropower resources for relicenses issued with open-ended articles, ${ }^{21}$ which allow FERC and agencies to impose further requirements at any time.

Capacity and generation losses at relicensing resulted from satisfying agency recommendations to release increased minimum bypass flows, release water through mandated fish passage facilities, restrict reservoir fluctuation, or limit downstream flow release fluctuations. Many projects lost power through a combination of these requirements. 


\section{Capacity}

As a result of modifying operations and/or flow patterns, many projects formerly operated to meet peak demands have been changed to partial peaking or run-of-river operation at relicensing. The result has been a loss of capacity available to meet critical peak demands for electricity. Although changing to run-of-river operation can result in increased generation if the turbines operate more total hours during the year, most of any increase will occur at non-critical, off-peak periods when the generation is less valuable. But these small gains are generally offset by the operation of the turbines at reduced efficiencies.

Figure 3-1 shows the number of projects gaining and losing capacity at relicensing from 1980 through $1996 .{ }^{19}$

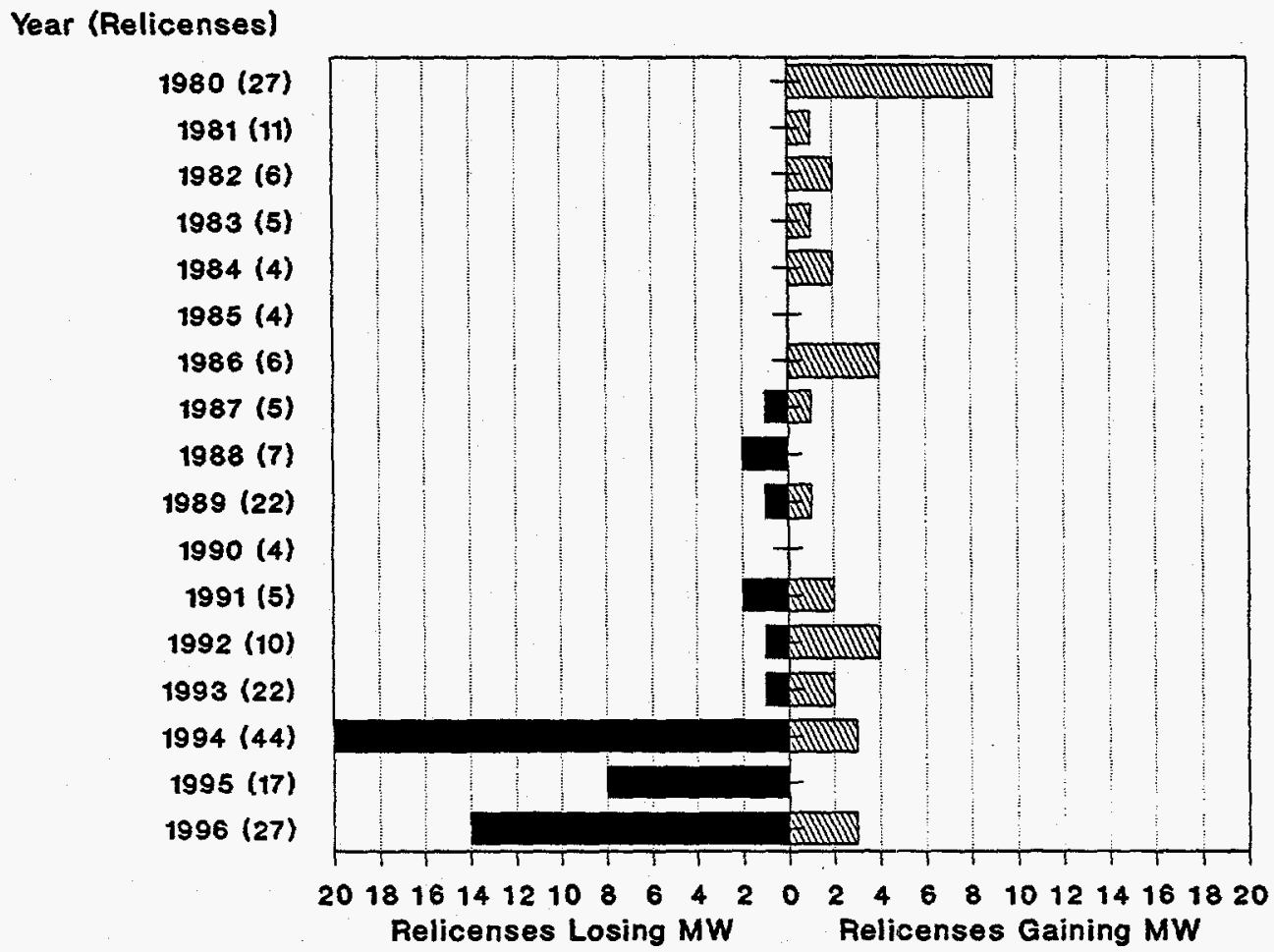

Figure 3-1. Projects Losing and Gaining

Capacity at Relicensing

\section{Relicensed Projects with Peaking Capacity Loss and Gain}

During the past 17 years (1980-1996), the FERC issued 226 relicenses with 6,498 MW of installed capacity. Sixty-three of these relicenses with 3,260 MW of capacity were 
issued during the immediate pre-ECPA years of 1980-1986. Nearly 30 percent of the pre-ECPA group, or 18 projects with a total of $1,944 \mathrm{MW}$, were operated to meet peak electricity demands. As a result of relicensing, the peaking capacity was expanded at three of these projects, and no project had its ability to meet peak demand reduced.

After ECPA was enacted, the outcome for relicensed projects changed dramatically. Since 1987, 163 projects totaling 3,238 MW have been relicensed by the FERC. Fifty-two of these projects with 1,859 MW were being operated to meet peaking demands. At relicensing, peaking capacity was added at four of these projects. However, the gains at two of these four projects were largely negated as a result of final license requirements, The remaining 48 peaking projects had their ability to meet peak demand reduced. Therefore, 96 percent of the peaking projects relicensed since ECPA (50 of 52) lost capacity. Thus, a consistent pattern has emerged where virtually every peaking project relicensed loses capacity.

Figure 3-2 shows the total number of peaking projects losing capacity at relicensing from 1980 through $1996 .^{19}$

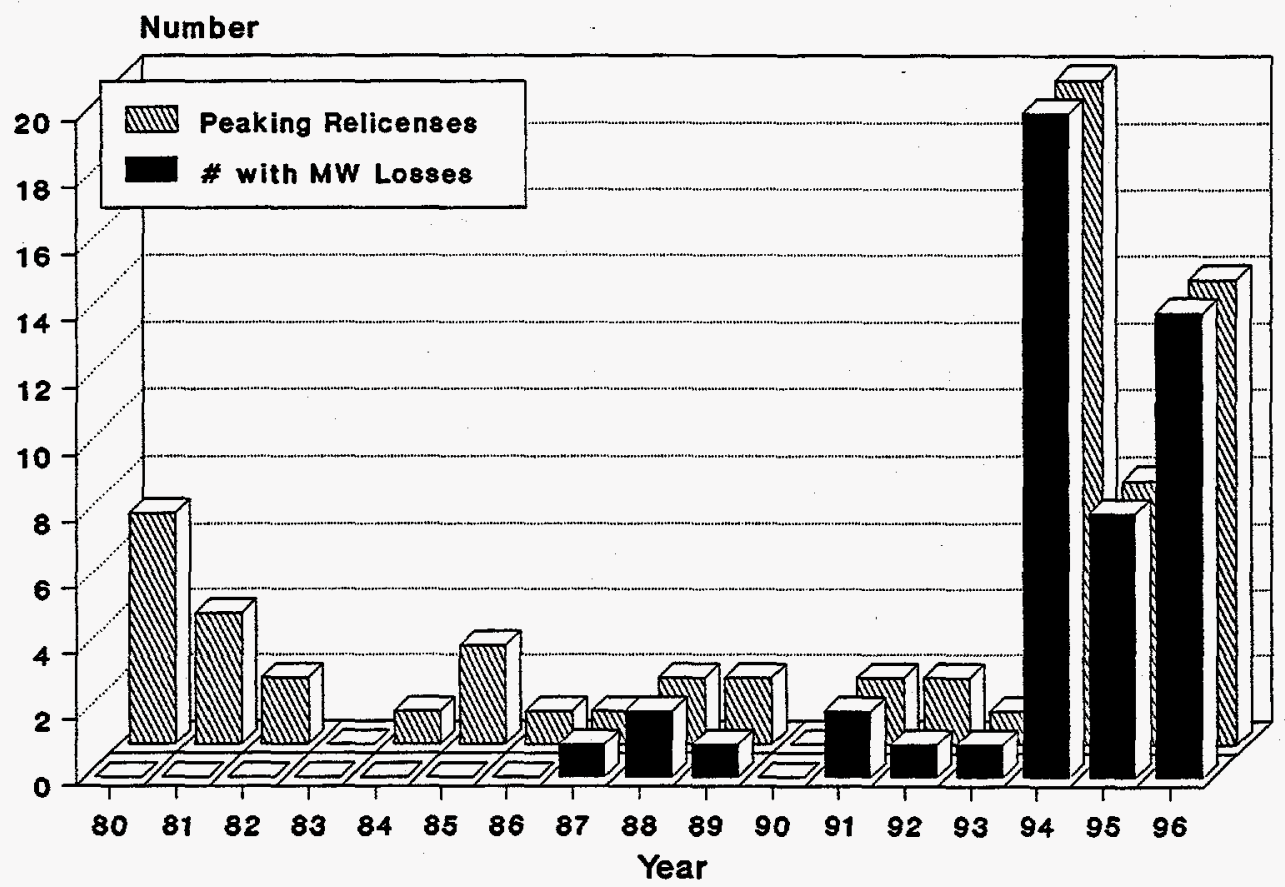

Figure 3-2. Peaking Projects Losing Capacity at Relicensing 


\section{Peaking Capacity Loss at Relicensing}

While hydropower projects are licensed for a given amount of installed capacity, it is their dependable capacity that is of greatest interest. Dependable capacity is the capacity that is available to meet peak system electrical load on demand. Of the $1,944 \mathrm{MW}$ of peaking capacity relicensed during the $1980-1986$ period, $1,167 \mathrm{MW}$ is estimated to be dependable. ${ }^{22}$ Of the $1,859 \mathrm{MW}$ of peaking capacity relicensed after ECPA (1987-1996), 1,115 MW is estimated to be dependable.

From 1980 through 1986, no dependable peaking capacity was lost at relicensing. Immediately after ECPA (1987-1993), five percent of the $108 \mathrm{MW}$ of the pre-relicensing dependable capacity was lost at relicensing. In the past three years (1994-1996), the percentage of dependable capacity lost at relicensing was double that of the previous six years. Ten percent of the 1,007 MW of dependable peaking capacity relicensed from 1994 through 1996 was lost during the process. The reduction at projects relicensed after ECPA ranged from 0.6 to 87.3 percent of their previous dependable peaking capacity.

Figure 3-3 shows the total amount of dependable peaking capacity lost for all projects from relicensing actions before and after ECPA, and the average capacity lost per project. $^{19}$

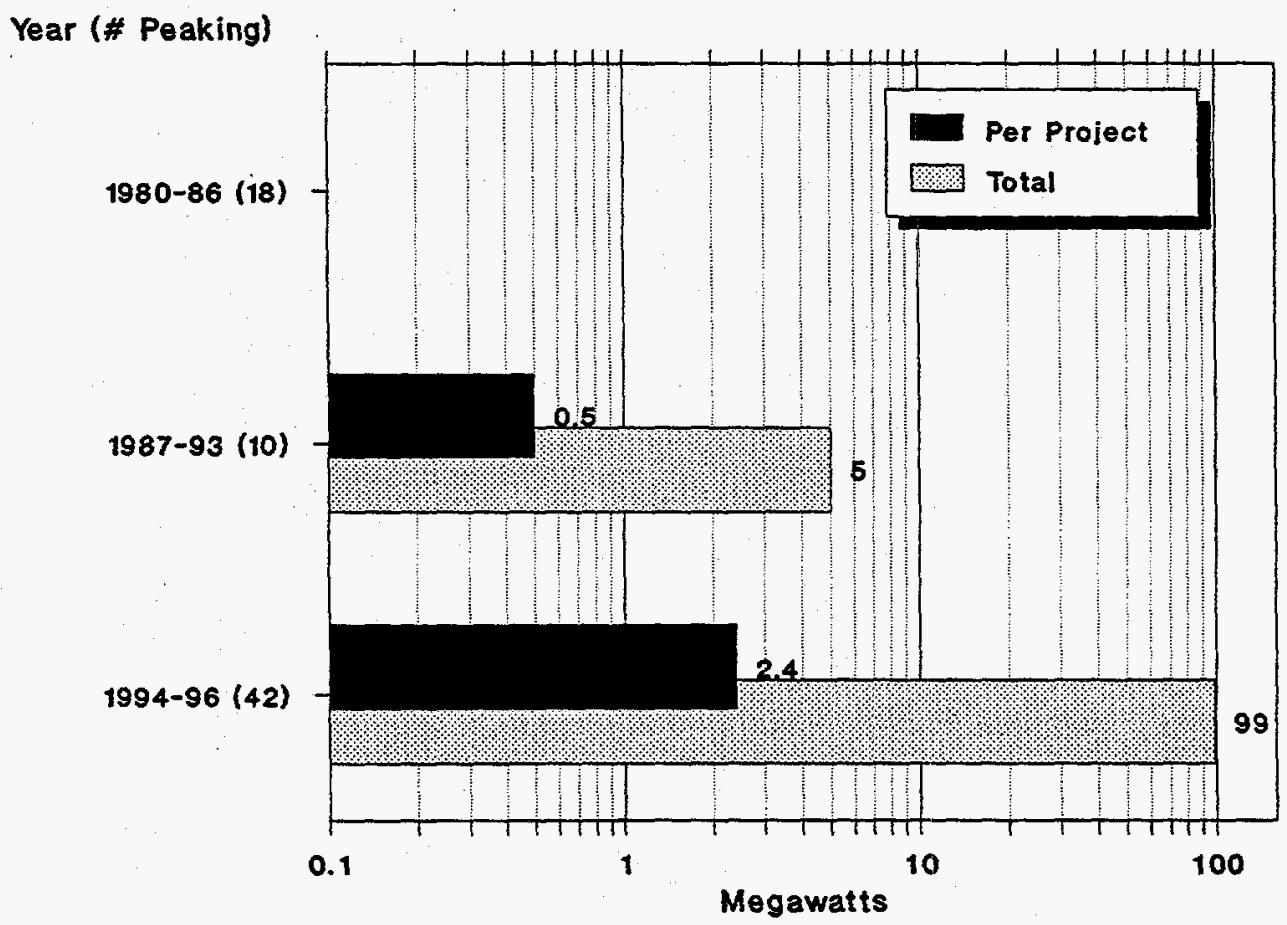

Figure 3-3. Dependable Peaking Capacity Lost at Relicensing 


\section{Run-of-River Capacity Lost from Licenses Surrendered}

The effects of ECPA also led to the surrender of licenses of both operating projects and newly licensed projects that were never built. Between 1980 and 1986, the license for one 4 MW project was surrendered. From 1987 through 1996, 502 licenses and exemptions were surrendered and 1,066 MW of capacity was lost. All of the licenses surrendered were for run-of-river projects. The increased time and cost of obtaining a license after ECPA and the increased mitigation requirements, which reduce the ability to develop projects to their full potential, have threatened the economic viability of many projects.

Figure 3-4 shows the total amount of run-of-river capacity lost from licenses surrendered before and after ECPA and the amount lost per project. ${ }^{23}$

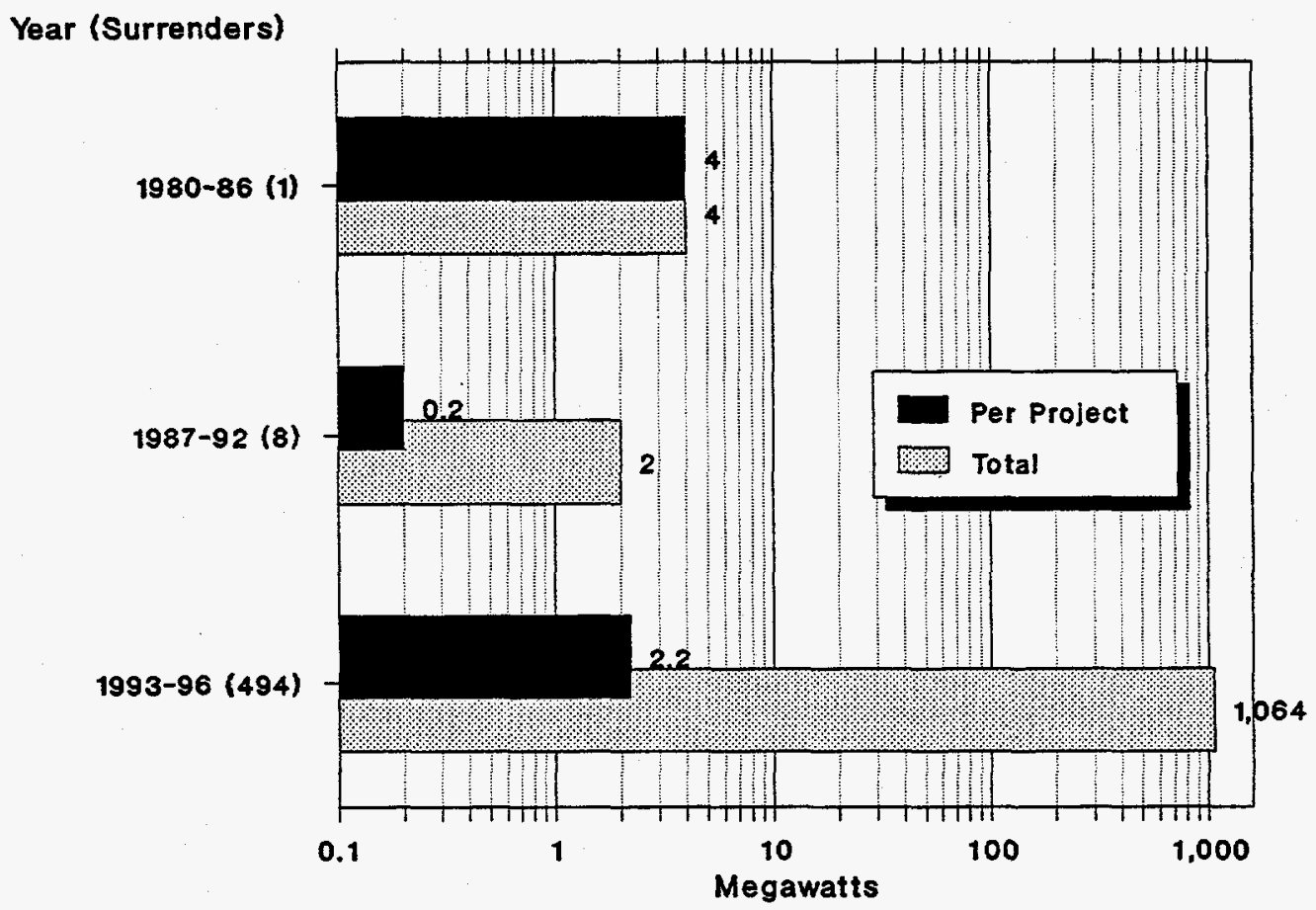

Figure 3-4. Capacity Lost due to Licenses Surrendered 


\section{Capacity Gain at Relicensing}

Not only do fewer projects relicensed after ECPA gain capacity, their gains are much smaller than those relicensed before 1986. Nineteen projects (or 30 percent of all 1980-1986 relicenses) gained capacity in the immediate pre-ECPA years of 1980-1986. Three peaking projects gained $255 \mathrm{MW}$, or an average of $85 \mathrm{MW}$ per project. Sixteen run-of-river projects, operated to provide baseload power, gained $184 \mathrm{MW}$, or an average of $11.5 \mathrm{MW}$ per project.

Sixteen projects (or 10 percent of all 1987-1996 relicensings) have gained capacity at relicensing since the passage of ECPA. Four peaking projects gained $21 \mathrm{MW}$, or an average of 5.2 MW per project. Twelve run-of-river projects gained $119 \mathrm{MW}$, or an average of $9.9 \mathrm{MW}$ per project.

Figure 3-5 shows the average capacity gained per project for run-of-river and peaking projects relicensed before and after ECPA. ${ }^{19}$

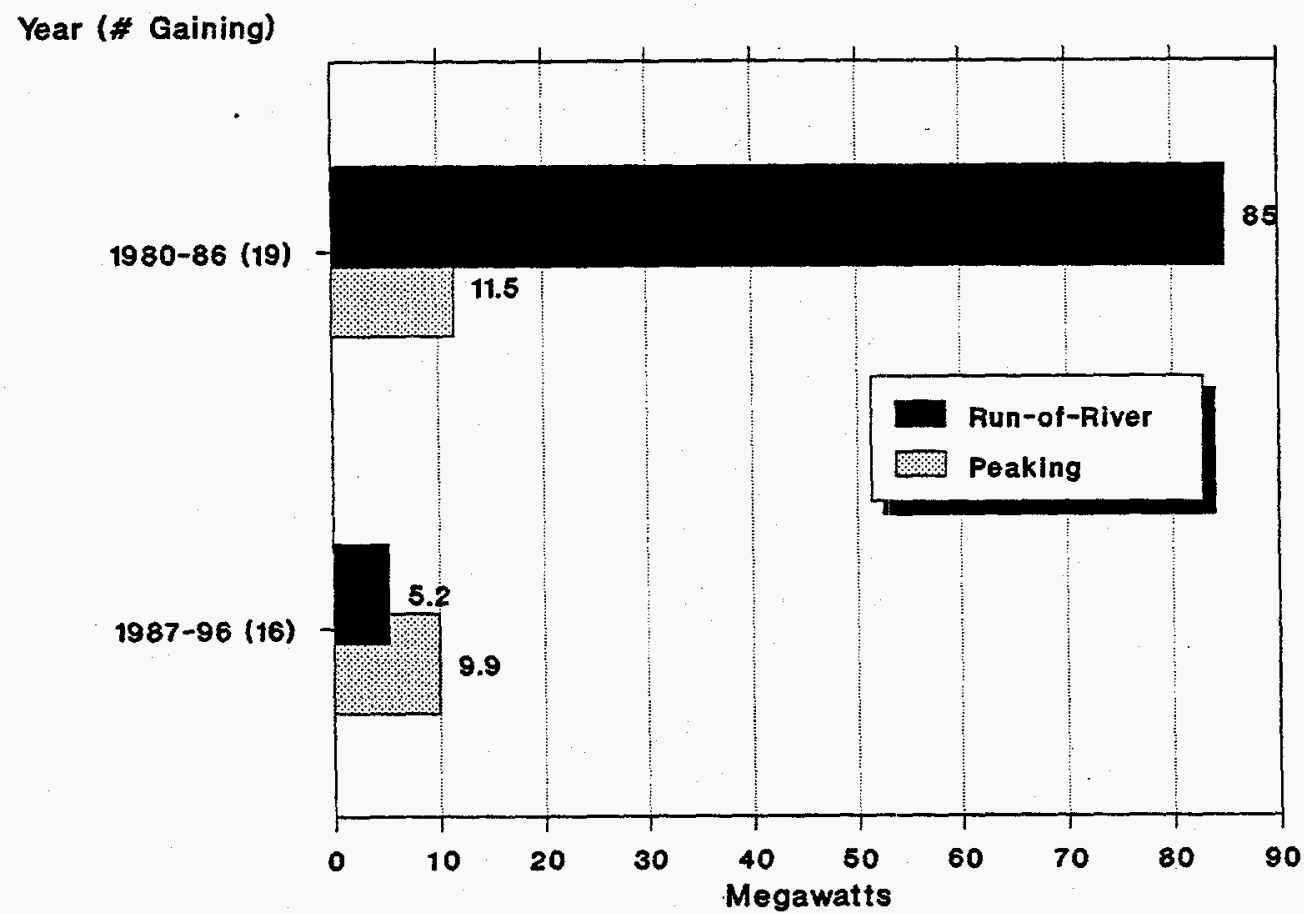

Figure 3-5. Average Capacity Gain Per Project Before and After ECPA 
Table 3-1 summarizes the Hydropower Capacity Losses from 1987 through 1996 and confirms that loss of power at relicensing is a post-ECPA phenomenon.

Table 3-1

Summary of Regulatory Effects on Hydropower Capacity

\begin{tabular}{|c|c|c|c|c|c|}
\hline & \multicolumn{5}{|c|}{ Pre-ECPA (1980-1986) } \\
\hline & $\begin{array}{c}\text { Relicensed } \\
\text { Capacity } \\
\text { (MW) }\end{array}$ & $\begin{array}{c}\text { Dependable } \\
\text { Capacity } \\
\text { (MW) }\end{array}$ & $\begin{array}{l}\text { Capacity } \\
\text { Lost } \\
\text { (MW) }\end{array}$ & $\begin{array}{c}\text { Capacity } \\
\text { Surrendered } \\
\text { (MW) }\end{array}$ & $\begin{array}{l}\text { TOTAL } \\
\text { Losses } \\
\text { (MW) }\end{array}$ \\
\hline Peaking Projects & 1,944 & 1,167 & 0 & 0 & 0 \\
\hline Run-of-River Projects & 1,316 & 0 & 0 & 4 & 4 \\
\hline \multirow[t]{3}{*}{ TOTALS } & 3,260 & 1,167 & 0 & 4 & 4 \\
\hline & \multicolumn{5}{|c|}{ Post-ECPA (1987-1996) } \\
\hline & $\begin{array}{c}\text { Relicensed } \\
\text { Capacity } \\
\text { (MW) }\end{array}$ & $\begin{array}{c}\text { Dependable } \\
\text { Capacity } \\
\text { (MW) }\end{array}$ & $\begin{array}{c}\text { Capacity } \\
\text { Lost } \\
\text { (MW) }\end{array}$ & $\begin{array}{c}\text { Capacity } \\
\text { Surrendered } \\
\text { (MW) }\end{array}$ & $\begin{array}{c}\text { TOTAL } \\
\text { LOSSeS } \\
\text { (MW) }\end{array}$ \\
\hline Peaking Projects & 1,859 & 1,115 & 104 & 0 & 104 \\
\hline Run-of-River Projects & 1,379 & 0 & 0 & 1,064 & 1,064 \\
\hline TOTALS & 3,238 & 1,115 & 104 & 1,064 & 1,168 \\
\hline
\end{tabular}




\section{Generation}

\section{Relicensed Projects with Generation Loss and Gain}

FERC approved the expansion for 19 of the 63 projects relicensed in the immediate pre-ECPA years (1980-1986). Two projects had their generation reduced at relicensing.

Since the enactment of ECPA, the outcome for relicensed projects has changed dramatically. Of the 163 projects relicensed by the FERC from 1987 through 1996, 21 projects gained generation. However, 105 lost generation. Much of the gain can be attributed to changing operations of these projects from peaking to run-of-river, which increases the amount of off-peak time the plants are operating. The losses resulted from required increases in water releases that must bypass the turbines or restrictions in water releases through the turbines. After ECPA, the number of projects with reduced generation at relicensing has increased until, in 1996, 90 percent of all projects relicensed lost generation.

Figure 3-6 shows the number of projects losing and gaining generation from relicensing actions from 1980 through $1996 .{ }^{19}$

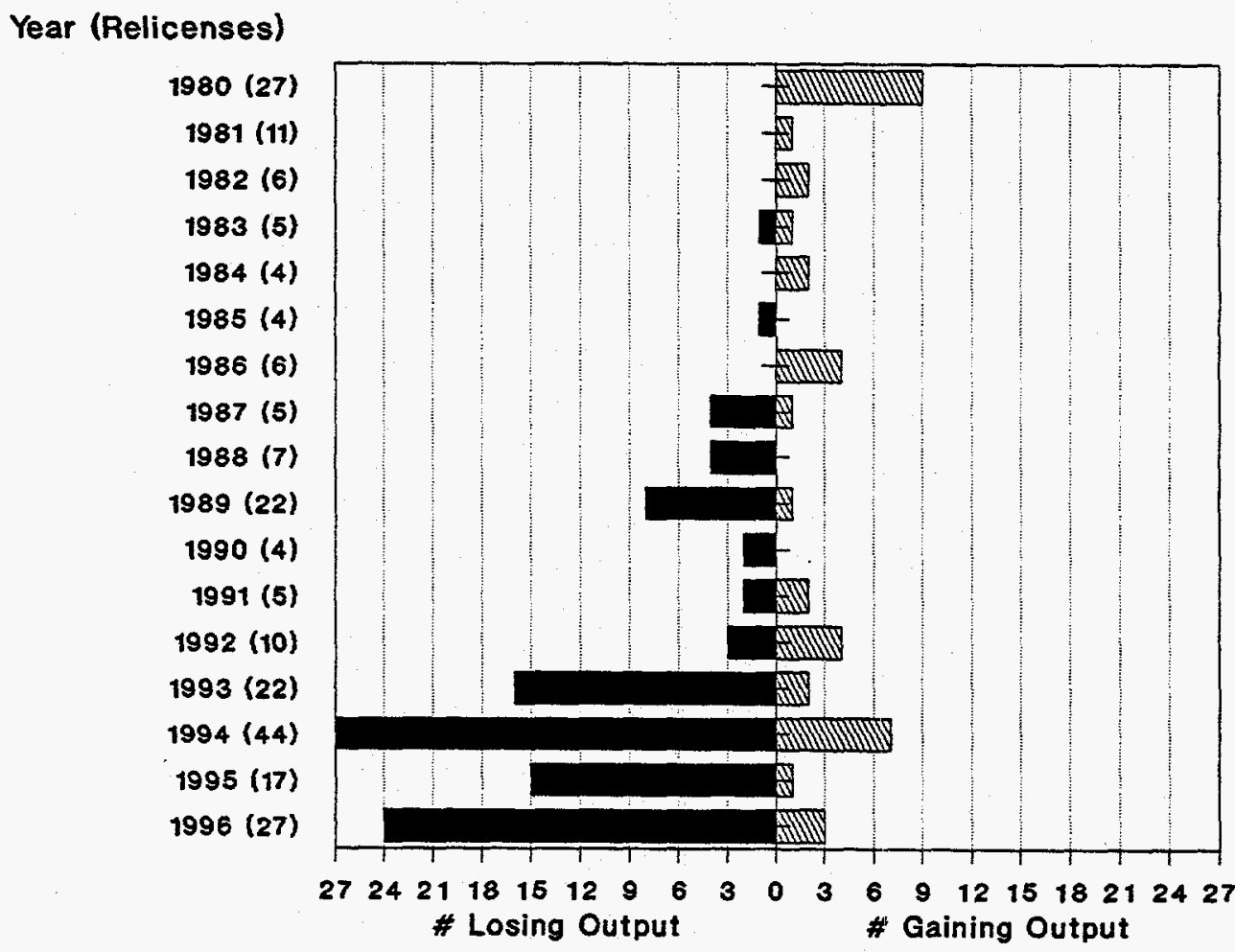

Figure 3-6. Projects Losing and Gaining Generation at Relicensing 


\section{Generation Loss at Relicensing}

Post-ECPA relicenses losing generation lost from 0.4 to 54.3 percent of their previous generation. The average reduction per project was 6 percent.

The 63 projects relicensed from 1980 through 1986 lost only one-half of one percent of their annual 11.7 billion kWhrs of pre-relicensing generation. In contrast, the 163 projects relicensed from 1987 through 1996 lost five percent of their annual 13.5 billion kWHrs of pre-relicensing generation.

Figure 3-7 shows the percentage of total pre-relicensing generation lost and the percentage of generation lost at each project when relicensed from 1980 through $1996 .{ }^{19}$ When comparing the pre-ECPA and post-ECPA periods, the loss of total pre-relicensing generation increased tenfold, from 0.5 percent to 5 percent. Average per-project losses before and after ECPA were about the same.

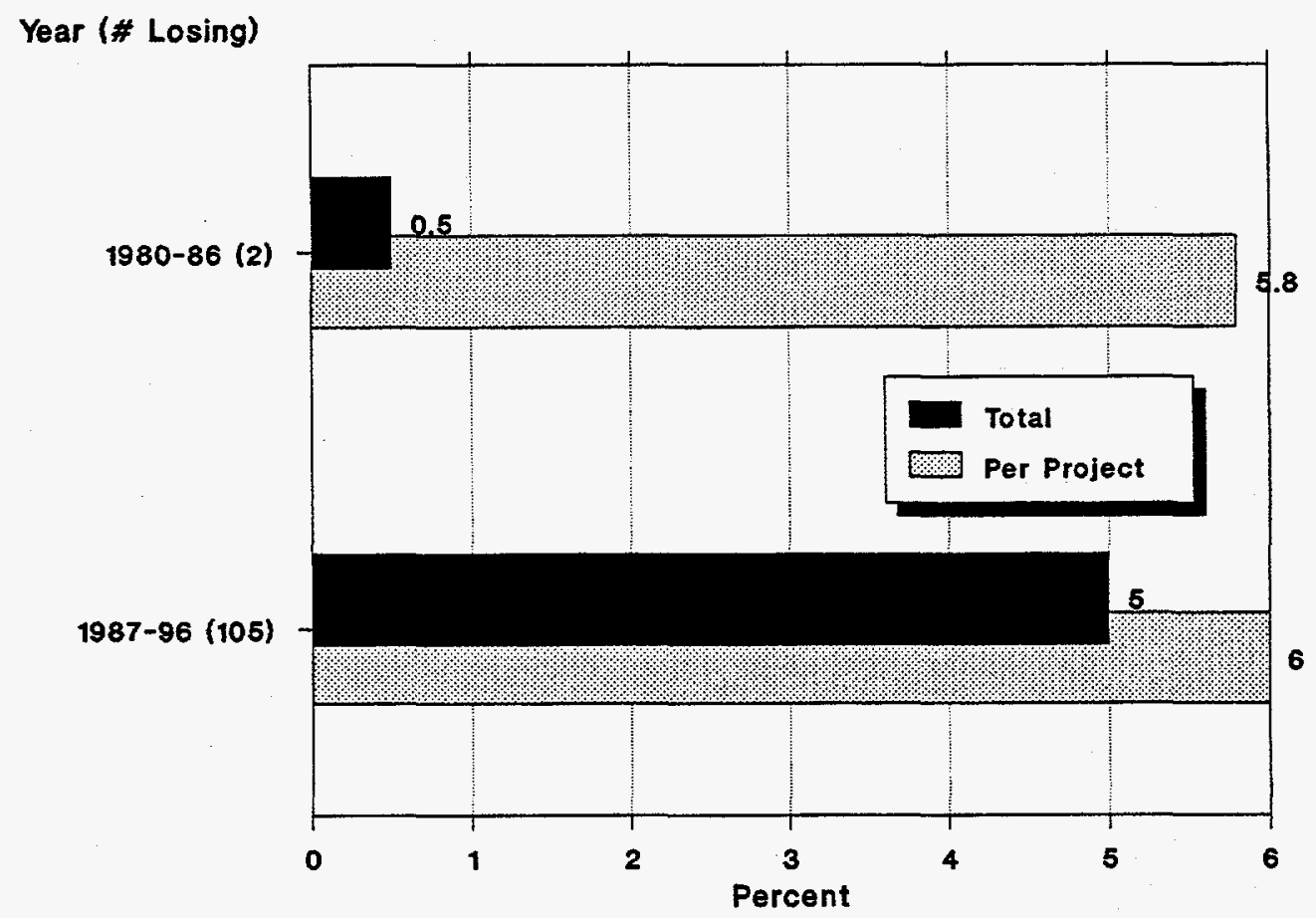

Figure 3-7. Percent Generation Loss Before and After ECPA 


\section{Generation Loss from Licenses Surrendered}

Between 1980 and 1986, only one license averaging an estimated 20 million kWHrs/ $\mathrm{Yr}$ of output was surrendered. From 1987 through 1996, 502 licenses and exemptions were surrendered with a resulting loss in generation estimated to be 4.7 billion kWHrs/Yr. ${ }^{24}$

Figure 3-8 shows the per project and total generation lost from surrendered projects since $1980 .^{25}$

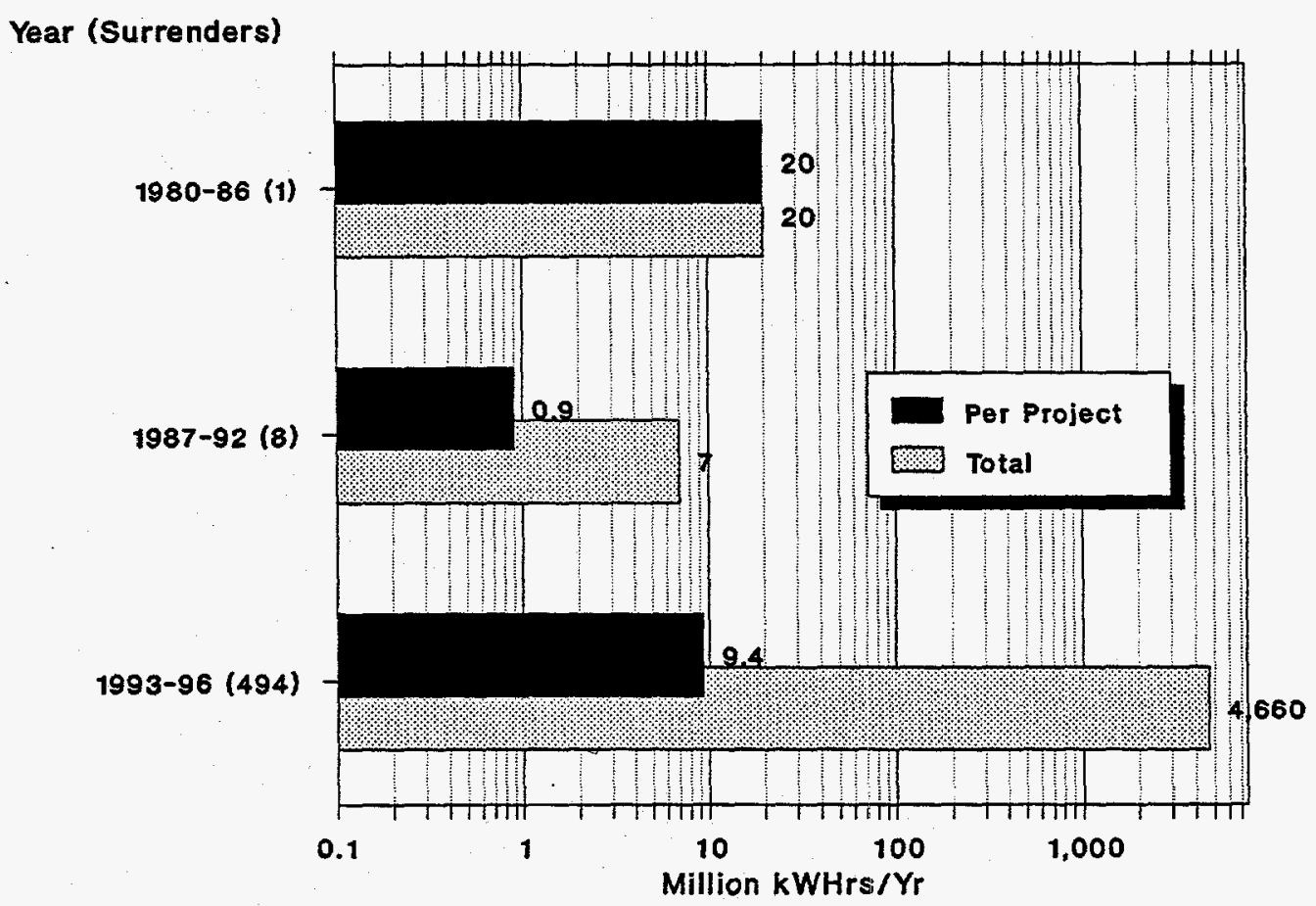

Figure 3-8. Generation Loss from Surrendered Licenses

Table 3-2 summarizes the total estimated hydropower generation lost from 1980 through 1996. Generation loss at post-ECPA relicensing was 10 times greater than that experienced in the immediate pre-ECPA period. Surrendered licenses amounted to 86 percent of the estimated annual losses. 
Table 3-2

Summary of Regulatory Effects on Hydropower Generation

\begin{tabular}{cc}
$\begin{array}{c}\text { Original } \\
\text { Generation } \\
\text { (Million } \\
\text { kWHrs/Yr) }\end{array}$ & $\begin{array}{c}\text { Generation } \\
\text { Lost } \\
\text { (Million } \\
\text { kWHrs/Yr) }\end{array}$ \\
\hline
\end{tabular}

11,671
(1987-1996)

TOTALS

Pre-ECPA

Post-ECPA
(1980-1986)
13,548

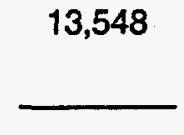

25,219

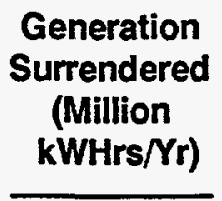

681

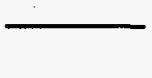

746
20

4,667

TOTAL

Losses

(Million

kWHrs/Yr)

85

5,348

4,687

5,433

\section{Generation Gain at Relicensing}

Not only did fewer projects relicensed after ECPA gain generation, their gains are much smaller than those relicensed before 1986. The 19 projects increasing generation at relicensing in the immediate pre-ECPA years realized an average gain of 41 million $\mathrm{kWHrs} / \mathrm{Yr}$ per project. The 21 projects increasing generation at relicensing since the passage of ECPA have gained an average of 21 million $\mathrm{kWHrs} / \mathrm{Yr}$ per project, or about half of that experienced prior to ECPA.

Figure 3-9 shows the total amount of generation gained for all projects from relicensing actions before and after ECPA and the average amount gained per project. ${ }^{19}$ 


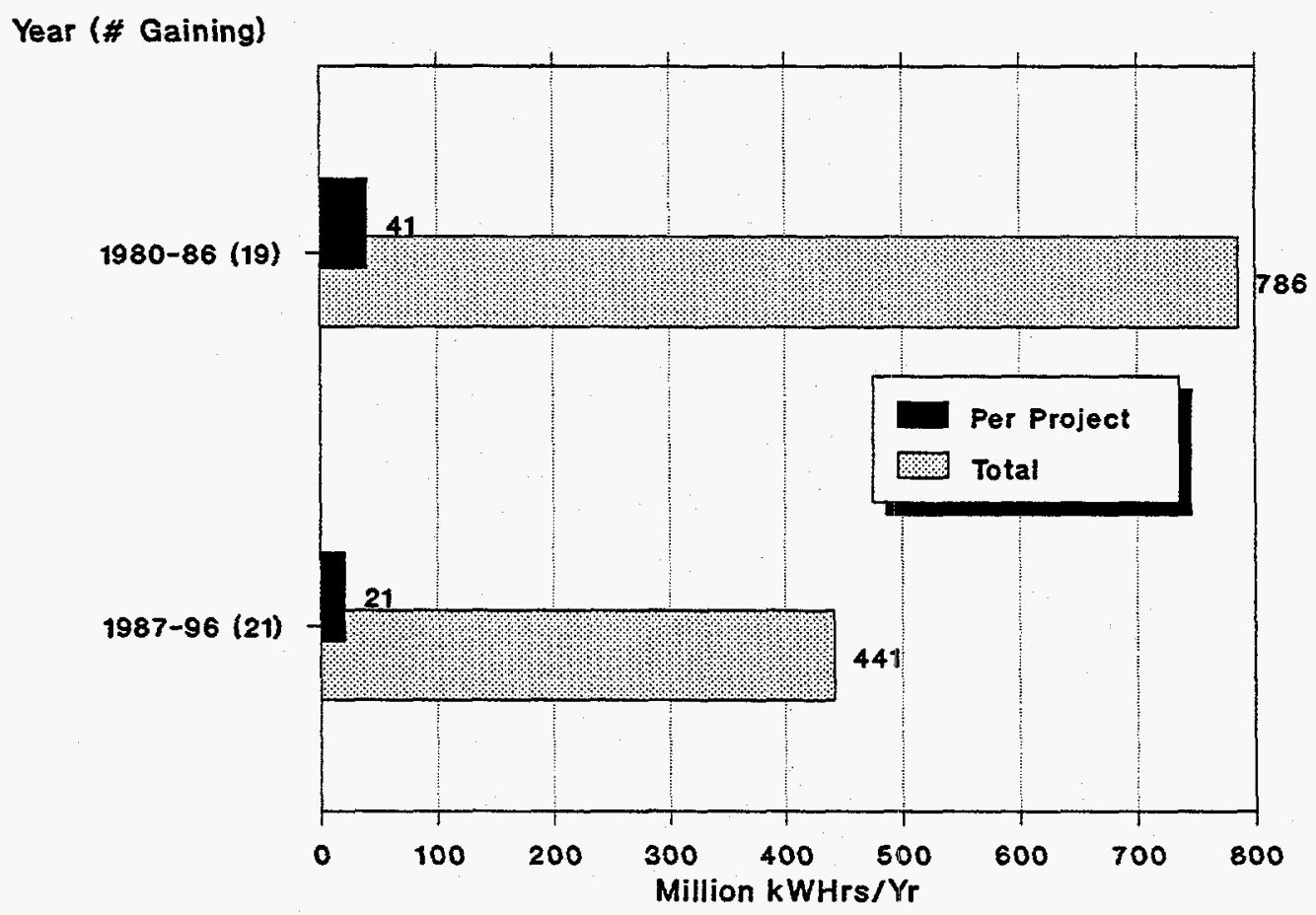

Figure 3-9. Generation Gain at Relicensing

\section{COSTS}

The most critical element of risk in hydropower development today is the rising cost associated with licensing and operating a hydropower project. This cost includes expenses associated with a lengthier and more burdensome licensing process, future uncertainty due to open-ended licensing requirements, the value of lost capacity and generation to satisfy agency requirements at relicensing, and other ongoing mitigation expenditures over the life of the license.

\section{License Processing Cost ${ }^{26}$}

The cost of licensing a hydropower project is directly related to the time spent in the licensing process and to the size of the project. The licensing process includes three primary cost elements: (1) the time cost of money; (2) administrative costs, and (3) technical analyses. 
The time cost of money is the financing charge that applicants must pay while they are pursuing their license. There is no reliable way to estimate what these costs will be; however, it is certain that the lengthened time for licensing most projects in recent years has added significantly to the cost of financing licensing efforts.

The administrative costs include all of the activities and preparation of documents that must be completed by the applicant in pursuit of the license. Administrative expenditures extend throughout the licensing process, and the magnitude of these costs is directly related to the length of the process. They include the cost of:

- Planning -- selecting the management team, compiling existing site information, conducting audits of records of project generation, operation and maintenance, and efficiency (for relicenses), and reviewing relevant statutes and regulations;

- Implementation of the licensing strategy - identifying and organizing tasks, preparing a schedule, estimating costs, identifying development options (upgrade options for relicenses), and evaluating the economics of the project; and

- Pursuing the process with FERC -- filing the application, consultation with FERC, and submitting supplemental information.

The technical analysis costs include:

- Consultation with FERC, resource agencies, and special interest groups;

- Conducting the agreed-upon studies -- applicants are now required to conduct fisheries and recreation studies in virtually all licensing cases; and

- Completing the application.

Technical analysis costs account for between 85 and 90 percent of all licensing costs. Total license processing costs are directly related to the size of the project and the number of agencies and special interests involved in the process.

\section{Cost of Longer Processing Time after ECPA}

Figures 2-3 and 2-4 show that license processing time more than doubled after the enactment of ECPA and relicenses issued in 1996 took an average of 4.5 years to process. ${ }^{23}$ 
The longer a project languishes in the hydropower licensing process, the greater the chance that new FERC regulation or policy will change the processing requirements and the greater the opportunity for additional intervention by resource agencies and special interests. For this reason, the cost of the growing environmental study requirements after ECPA are included as a part of the cost of the lengthened processing time.

Figure 3-10 shows the increased cost of licensing from 1981 through 1996 for a range of project sizes.26 These costs are in current dollars and are adjusted for the effects of inflation. From 1987 through 1996, the real cost of licensing about doubled for all project sizes.

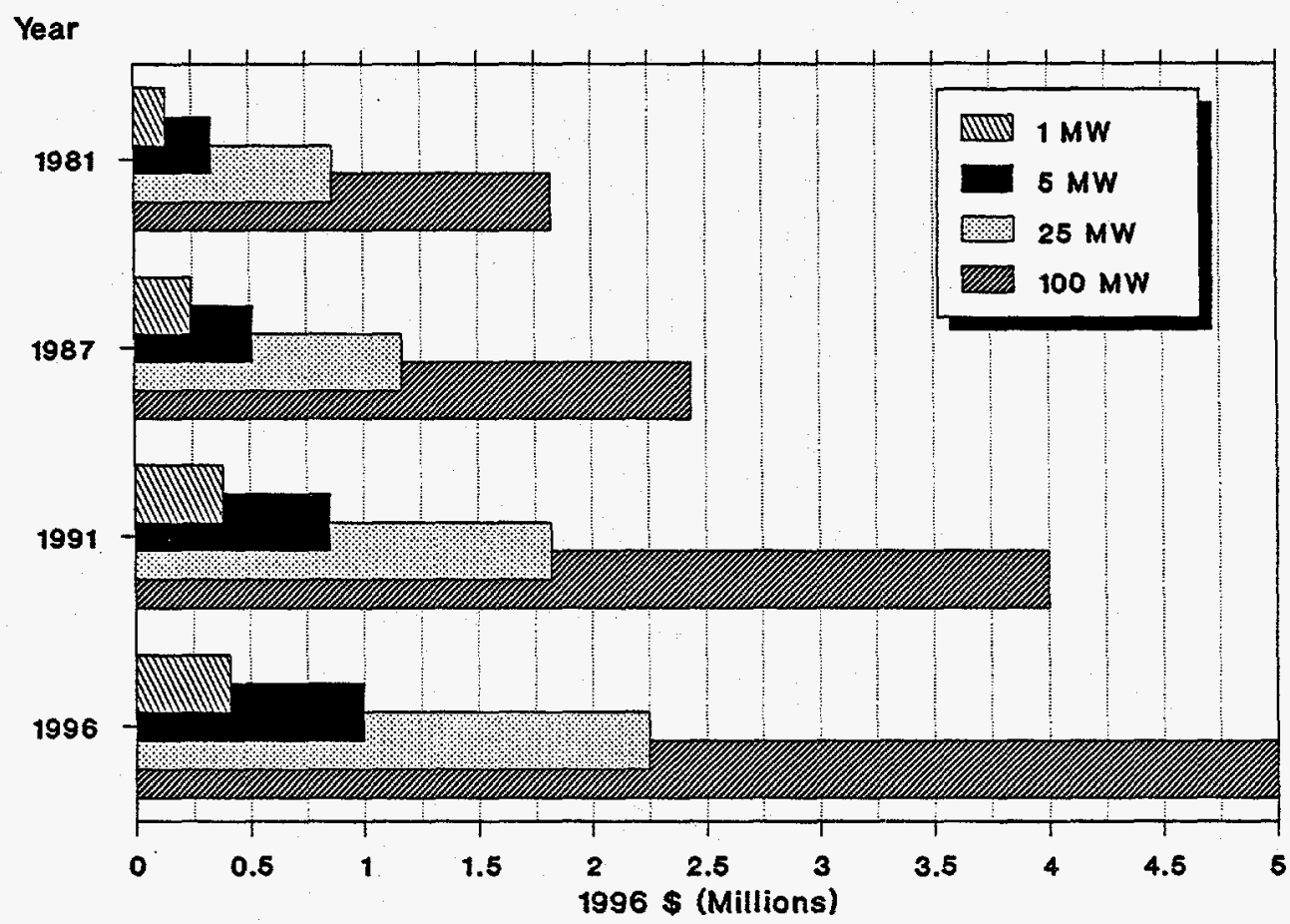

Figure 3-10. Trends in Average Costs to Obtain a License

\section{Licensing and Study Costs by Project Size}

Total licensing costs were obtained for nearly 180 projects licensed or relicensed between 1980 and 1996. These costs were adjusted for the effects of inflation and plotted in 1996 dollars on a log-log scale according to project size. A best-fit curve representing the individual data points was then drawn. Two curves were drawn parallel to the best-fit line (one above and one below) so that 90 percent of the individual data points were included between these curves. The result is the shaded area shown in Figure 3-11. ${ }^{26}$ 
Figure 3-11 shows the range of total licensing costs by size of project. For projects of a given size, the cost range shown in Figure 3-11 can be narrowed using the following factors:

- Lower head projects with a powerhouse integral to the dam or with short bypass canals or penstocks tend toward the lower half of the range;

- High head projects with long penstock or canai diversions tend toward the upper end of the range

- Projects in western states tend to the upper third of the range;

- Projects in southeastern states tend toward the lower half of the range; and

- Projects in New England and midwestern states generally fall in the middle half of the range.

$1996 \$$ (Millions)

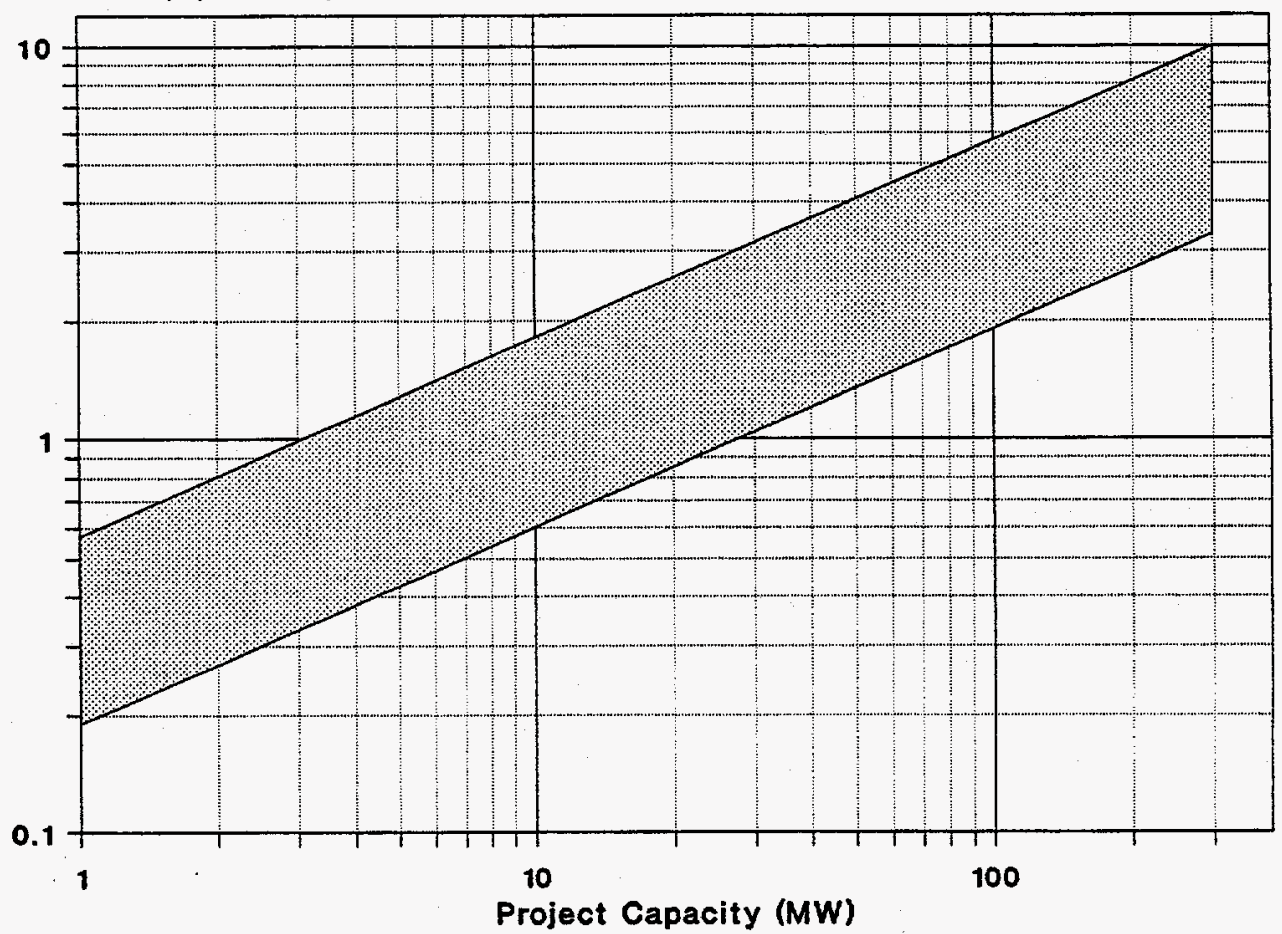

Figure 3-11. Range of Licensing Cost by Project Size 
The licensing cost data used to prepare Figure 3-11 were reviewed to obtain details of the costs for different types of licensing studies. Based on this review, Figure 3-12 was prepared. Figure 3-12 shows average total licensing costs, average total study costs, and average costs of various types of studies for projects of varying size.

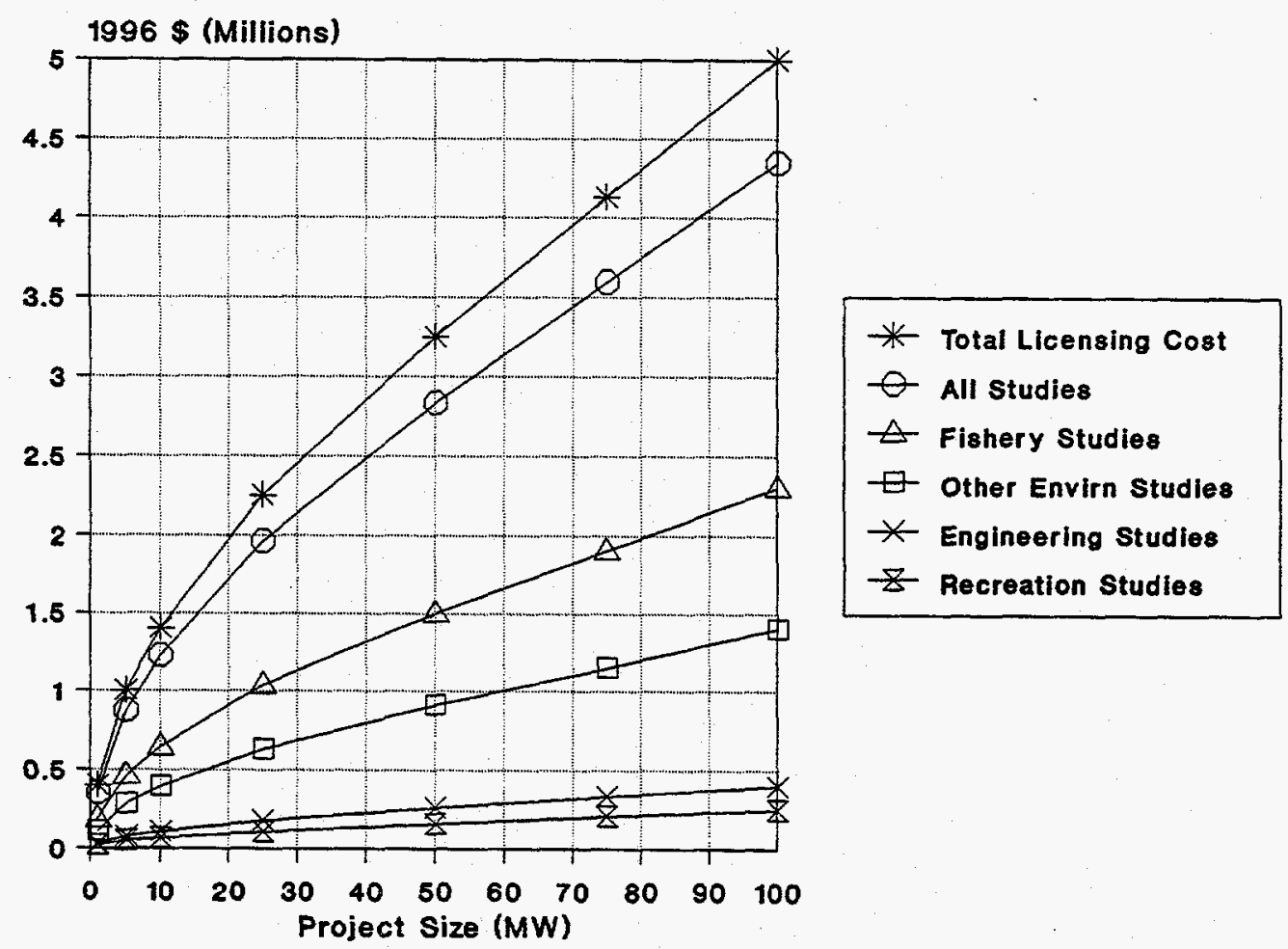

Figure 3-12. Average Licensing Expenditures for Studies

As Figure 3-12 shows, the costs of licensing studies have continued to increase to the present time. And there is no indication that this trend is ending. In the five years immediately following the passage of ECPA, licensing costs increased 70 percent. During the past five years, licensing costs have increased another 25 percent. These increases result from lengthened processing time, greater numbers of studies, and more extensive study requirements.

\section{License and Relicense Processing Costs (1980-1996)}

An important element of the cost of hydropower regulation is related to license processing. To estimate total regulatory costs for the 1980-1996 period, the cost of processing all licenses for new projects in service, licenses surrendered, and relicenses issued during this period was required. This was accomplished by developing an equation relating average licensing cost to project size from the Figure 11 data, and then applying this equation to individual projects to estimate their licensing cost. ${ }^{27}$ 
Total estimated license and relicense processing costs for the 1980-1996 period are summarized in Table 3-3.

\section{Cost of Peaking Capacity Lost at Relicensing}

Capacity losses at relicensing are described in Figure 3-3. To estimate the value of this lost capacity, it was necessary to first compute the amount of on-peak generation produced by this capacity. ${ }^{28}$ Then the amount of lost peaking generation was multiplied by the power value ${ }^{29}$ to determine the total costs of these losses. The result is then multiplied by 30 years to determine the costs of the losses over a 30 -year license period.

These 30-year costs are summarized in Table 3-3.

\section{Cost of Lost Generation}

\section{At Relicensing}

The generation losses at relicensing are discussed on page 3-9. To compute the value of this lost generation, the power value ${ }^{29}$ is multiplied by the amount of generation lost. The result is then multiplied by 30 years to determine the costs of the losses over a 30-year license period.

Total 30-year costs of generation lost at relicensing are summarized in Table 3-3.

\section{From License Surrenders}

Generation losses due to license surrenders are described on pages 3-9 and 3-10. To compute the value of this lost generation, the amount of generation lost is multiplied by the power value, ${ }^{29}$ and then this result is multiplied by 30 years to take into account the cost of the losses over a 30 -year licensing period.

These 30-year costs are summarized in Table 3-3 below.

\section{Other Mitigation Costs at Relicensing}

The value of capacity and generation lost at relicensing are costs of mitigation. However, there are additional mitigation costs for license requirements that are intended to substitute benefits for the effects of the project on the environment. 
Mitigation requirements in relicenses after ECPA can include the installation of fish passage facilities, improvement of fish habitat, implementation of fish protection measures, stocking of fish for species restoration and enhancement, monitoring, water quality improvements, wildlife management plans, wildlife habitat improvements, protection of cultural and historical sites, implementation of new recreation plans, construction of new recreation facilities, and establishment of funds for a variety of future purposes. The economic viability of any individual hydropower project is related to the size of the project and the amount of power it can generate. Thus, larger projects have the ability to sustain higher total mitigation costs.

At relicensing, mitigation costs are often imposed to the point where a project has only marginal economic value over the life of the license. Recent FERC relicenses include statements indicating that mitigation requirements have been increased to the point where the economic viability of the project is threatened. For example, the relicense order for Project 2579 (issued December 23,1996) states: ".....the existing Twin Branch project would have a net annual benefit of $\$ 143,000$.... When licensed in accordance with the conditions adopted herein, the project would produce...... net annual benefit of about $\$ 33,100 \ldots$... While the economic benefits with the required mitigation and enhancement measures appear to be minimal, I conclude ......that it is in the public interest to license the project."

In some cases, the FERC has issued licenses where their own analysis shows that the mitigation costs exceed the value of the project. The relicense for Project 2486 (December 19,1995) states: "We conclude that while, ....the Pine Project produces power at a cost greater than the likely cost of alternative power, the project remains a viable energy-producing resource....." And, for Project 2332 (June 12, 1996): "If licensed in accordance with the conditions adopted herein, the project will ..... produce .....energy at an annual cost of $\$ 1.65$ million......, or about $\$ 367,000$......more than the current cost of alternative power sources....."

A detailed analysis of the mitigation costs imposed on all 88 relicenses issued by the FERC in the period 1994-1996 was conducted. These costs were then multiplied by 30 years to reflect their effect for a 30-year licensing period. No reliable pattern of mitigation cost by project size was evident from the data. Figure 3-13 shows the wide scatter of total 30-year mitigation costs for these relicenses when these costs are plotted according to installed plant capacity on a log-log scale.

To view an example of the broad range of costs encountered, select the $4 \mathrm{MW}$ line on the horizontal axis of Figure 3-13 and trace this line vertically. The data points plotted slightly to the left and right of this line describe 30 -year costs ranging from $\$ 30,000$ to $\$$ 5 million for the same sized project. Similarly, for $40 \mathrm{MW}$ projects, the costs range from $\$ 400,000$ to $\$ 50$ million. 


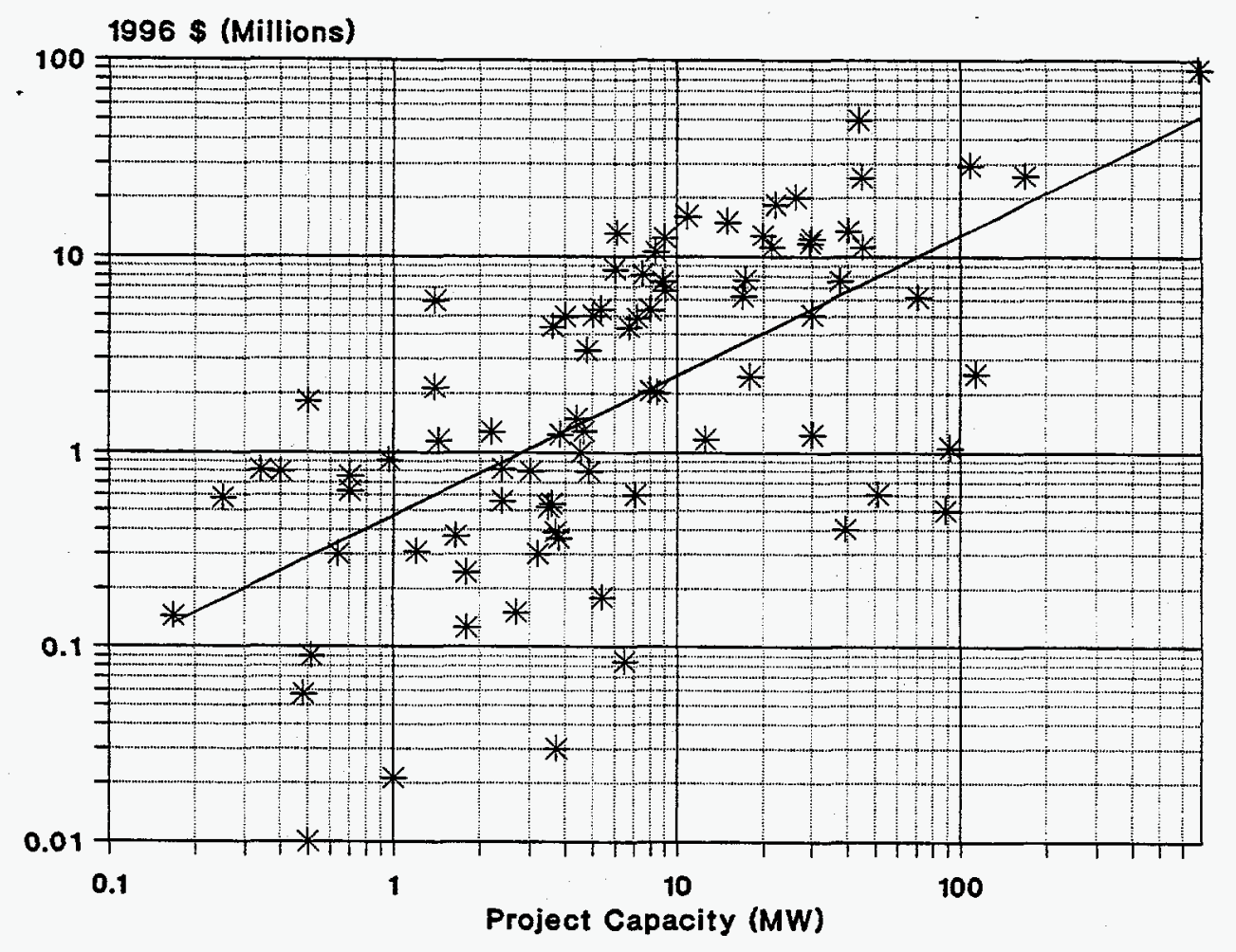

Figure 3-13. 30-Year Mitigation Costs by Project Size

Total 30 -year mitigation costs for the 88 relicenses issued by the FERC in the period 1994-1996 are known. To estimate mitigation costs for other time periods, an equation relating 30-year mitigation cost to project size from the data shown in Figure 3-13 was developed, and then this equation was applied to individual projects subject to relicensing in other time periods to estimate their mitigation costs. ${ }^{30}$

The mitigation costs for all projects relicensed from 1980 through 1996 are summarized in Table 3-3.

\section{Annual Charges}

Additional costs to licensees are the annual charges imposed by the FERC. These charges not only pay for FERC's hydropower-related operations, but they also pay for the licensing-related activities of other federal agencies that are reported to the FERC for collection. Annual charges for the 1980-1996 period are shown in Table 3-3. These costs are based on actual annual charges collected by the FERC during 1980-1996. ${ }^{31}$ 
Table 3-3 presents a summary of the 30-year costs of hydropower regulation in 1996 dollars for those actions occuring in the period 1980-1996.

Table 3-3

30-Year Costs of Regulatory Actions (1980-1996)

(\$ - Millions)

\begin{tabular}{|c|c|c|c|c|c|}
\hline & \multicolumn{2}{|c|}{$\begin{array}{l}\text { Pre-ECPA } \\
(1980-86)\end{array}$} & \multicolumn{2}{|c|}{$\begin{array}{c}\text { Post-ECPA } \\
(1987-96)\end{array}$} & \multirow{2}{*}{$\frac{\text { TOTALS }}{(1980-96)}$} \\
\hline & Relicensing & Other* & Relicensing & Other* & \\
\hline Lost Capacity & 0 & - & 240 & $\cdots$ & 240 \\
\hline Lost Generation & 41 & 13 & 529 & 2,978 & 3,561 \\
\hline License Processing & 168 & 156 & 224 & 419 & 967 \\
\hline Mitigation & 518 & - & 1,159 & $-\cdots$ & 1,677 \\
\hline Annual Charges & & 68 & & & 631 \\
\hline GRAND TOTAL & & & & & 7,076 \\
\hline
\end{tabular}




\section{Section 4 THE OUTLOOK FOR HYDROELECTRIC POWER}

Based on the regulatory trends from 1980 through 1996 and the effect of relicensing on the hydropower resource in the 10 years after ECPA, we have predicted losses of capacity and generation and the cost of these losses to the U. S. for the years 1997-2010. These predictions are conservative, as they do not include any losses from license surrenders that may occur during this period and do not consider the effects of future inflation and interest rates.

\section{PROJECTS AT RISK}

Table 4-1 shows that by 2010,520 existing plants totalling 22,217 MW and generating about 106 billion $\mathrm{kWHrs} / \mathrm{Yr}$ will be at risk in the relicensing process. This is 28 percent of the operating plants under FERC juridiction and these plants include more than 62 percent of all capacity and two-thirds of all average annual generation now licensed by the FERC.

Table 4-1

Relicense Applications Pending and Licenses Expiring (1997-2010)

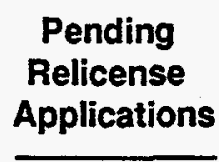

Projects

Plants

Capacity (MW)

Generation (Billion kWHrs/Yr)
71

131

2,728

16.76
Licenses

Expiring

(1997-2010)

239

389

19,489

89.10
TOTALS

310

520

22,217

105.86

\section{PROJECTED CAPACITY AND GENERATION LOSSES}

Environmental assessments and environmental impact statements prepared for the relicensing process describe the type of project operation (e.g., peaking or run-ofriver) and the effect of new license conditions on future power production. However, records maintained by the FERC do not distinguish between peaking and run-of-river projects. Therefore, peaking projects first had to be identified to estimate the capacity losses for upcoming peaking relicenses. This was done by: 1) computing the plant 
factor using FERC data for all plants with applications pending and those with licenses expiring between now and 2010, and 2) identifying those projects with a typical annual plant factor of 25 percent or less under the assumption that peaking plants operated within this range. This enabled us to estimate that the total MW of peaking capacity facing relicensing was $100 \mathrm{MW}$ for pending applications and 3,220 MW for licenses expiring in the next 14 years. Based on the experience since ECPA, five percent of the peaking capacity for these projects will be lost at relicensing.

The remaining projects are assumed to operate in the run-of-river mode. Based on the experience since ECPA, 5 percent of all generation subject to relicensing will be lost at relicensing.

Table 4-2 shows the projected losses of capacity and generation for those resources facing relicensing shown in Table 4-1.

\section{Table 4-2 \\ Projected Energy and Capacity Losses (1997-2010)}

\section{Pending \\ Relicense \\ Applications}

Capacity (MW)

Generation (Billion $\mathrm{kWHrs} / \mathrm{Yr}$ )
5

0.84
License

Expirations

(1997-2010)

161

4.46
TOTALS

166

5.30

\section{PROJECTED VALUE OF CAPACITY AND GENERATION LOST}

Using January 1996 regional power values, ${ }^{29}$ the values for the projected capacity and generation losses for a 30-year license period were calculated. The results are shown in Table 4-3. 
Table 4-3

30-Year Costs for Pending Relicenses and Licenses Expiring (1997-2010) (\$ - Millions)

\begin{tabular}{lcccc} 
& $\begin{array}{c}\text { Pending } \\
\text { Relicense } \\
\text { Applications }\end{array}$ & & $\begin{array}{c}\text { License } \\
\text { Expirations } \\
(1997-2010)\end{array}$ & TOTALS \\
\cline { 2 - 3 } License Processing & 200 & 882 & 1,082 \\
Lost Capacity & 39 & 1,477 & 1,516 \\
Lost Generation & 793 & 3,528 & 4,321 \\
Mitigation & 795 & 4,157 & 4,952 \\
Annual Charges & 164 & 1,169 & 1,333 \\
\hline TOTALS & $\underline{1,991}$ & 11,213 & 13,204
\end{tabular}

\section{PROJECTED ADDITIONAL COSTS OF THE REGULATORY PROCESS}

In determining the total cost to the country of hydropower regulation for these upcoming years, the associated costs of the licensing process, mitigation to satisfy the relicense requirements, and annual charges paid to the FERC by licenses must be considered.

- The projected cost of the license processing ( $\$ 1.082$ billion, Table 4-3) is derived using the equation relating licensing cost to project capacity ${ }^{27}$ and applying this equation to the capacity of each project to be relicenses before 2010.

- The projected cost of mitigation ( $\$ 4.952$ billion, Table 4-3) is derived using the equation relating project mitigation costs for 30 years to project capacity ${ }^{30}$ and applying this equation to the capacity of each project to be relicensed before 2010 .

- The projected cost of annual charges paid to the FERC by licensees ( $\$ 1.333$ billion, Table 4-3) is derived from the actual costs in 1996. These costs, which averaged about $\$ 2$ per installed $\mathrm{kW}$ for each licensed project, was applied to the capacity of each project to be relicensed before 2010 . 
The total projected cost of these items, based on a 30-year license life, is $\$ 7.367$ billion for all projects with a relicense application pending or whose license will expire from 1997 through 2010 . These conservative projected processing and regulatory costs, based on 1996 dollars, are shown in Table 4-3.

\section{SUMMARY (1997-2010)}

Based on regulatory trends from 1980 through 1996, the U.S. can expect to lose another 5.3 billion $\mathrm{kWHr} / \mathrm{Yr}$ of hydroelectric generation and $166 \mathrm{MW}$ of dependable capacity at FERC-licensed hydropower plants over the next 14 years. These losses are conservatively projected to cost $\$ 5.837$ billion over the 30-years that these licenses will be in effect. Additional processing and regulatory costs associated with these projects (as described above) will amount to $\$ 7.367$ billion. The total predicted costs to the U. S. for for hydropower regulatory actions during the period 1997 through 2010 is $\$ 13.204$ billion (Table 4-3).

\section{PROJECTED VALUE OF HYDROPOWER RESOURCE LOSSES (1980-2010)}

In determining what level of power loss is acceptable in the relicensing process, the FERC, resource agencies and others use a case-by case yardstick to evaluate what level of loss a project can sustain. The following tables are intended to provide a global view of the loss of total hydropower resources over the long term.

Table 4-4 gives a summary of the actual capacity and generation losses for all U.S. hydropower facilities subject to the regulatory process from 1980 through 1996 and the projected losses for those with relicense applications pending or licenses expiring from 1997 through 2010.

Table 4-4

Summary of Historical and Projected Capacity and Generation

Losses from Regulatory Actions (1980-2010)

\begin{tabular}{lcccc} 
& $\begin{array}{c}\text { Historical } \\
\text { Losses } \\
(1980-1996)\end{array}$ & & $\begin{array}{c}\text { Projected } \\
\text { Losses } \\
(1997-2010)\end{array}$ & TOTALS \\
\cline { 2 - 2 } Capacity Loss (MW) & 1,172 & & 166 & 1,334 \\
Generation Loss (Billion kWHrs/Yr) & 5.43 & 5.30 & 10.73
\end{tabular}

Table 4-5 summarizes the cost of these losses to the country. 
Table 4-5

30-Year Costs for the Historical and Projected Costs of Regulatory Actions (\$ - Millions)

\begin{tabular}{|c|c|c|c|}
\hline & $\begin{array}{c}\text { Historical } \\
\text { Regulatory } \\
\text { Costs } \\
(1980-96)\end{array}$ & $\begin{array}{c}\text { Projected } \\
\text { Regulatory } \\
\text { Costs } \\
(1997-2010)\end{array}$ & TOTALS \\
\hline License Processing & 967 & 1,082 & 2,049 \\
\hline Lost Capacity/Generation & 3,801 & 5,837 & 9,638 \\
\hline Mitigation & 1,677 & 4,952 & 6,629 \\
\hline Annual Charges & 631 & 1,333 & 1,964 \\
\hline TOTALS & 7,076 & 13,204 & 20,280 \\
\hline
\end{tabular}

\section{ESTIMATED UNDEVELOPED U. S. HYDROPOWER POTENTIAL}

Recent estimates of the undeveloped potential of hydropower resources in the U.S. and some predictions of development that will occur in the future are summarized in Table 4-6. These estimates show that there is sufficient potential to increase the existing hydropower resource by more than 45 percent given a streamlined licensing process and technology advancements.

Table 4-6

Estimated Undeveloped Hydropower Potential

\begin{tabular}{|c|c|c|}
\hline Source & $\begin{array}{c}\text { Estimated } \\
\text { Potential } \\
\text { Available for } \\
\text { Development } \\
\text { (MW) }\end{array}$ & $\begin{array}{l}\text { Projected New } \\
\text { Development } \\
\text { (MW) }\end{array}$ \\
\hline $\begin{array}{c}\text { SERI }^{32} \\
\text { (1990 Estimates) }\end{array}$ & $\begin{array}{c}37,000 \\
(1990-2030)\end{array}$ & 8,000 \\
\hline $\begin{array}{c}\text { INEL }^{33} \\
\text { (1997 Estimates) }\end{array}$ & 35,000 & - \\
\hline $\begin{array}{c}\text { ElA }^{34} \\
\text { (1993 Estimate) }\end{array}$ & - & $\begin{array}{c}4,000 \\
(1990-2010)\end{array}$ \\
\hline
\end{tabular}




\section{IMPEDIMENTS AND ISSUES IN HYDROELECTRIC DEVELOPMENT}

This report (Table 4-6) shows that there is a conservatively estimated $35,000 \mathrm{MW}$ of undeveloped hydropower potential. It is the clear message of this report that the U.S. is losing power with each relicensing of a hydropower plant and that new development has virtually disappeared.

The analyses contained in the present report show that many impediments cause uncertainty and expense to hydropower developers sufficient to threaten the viability of their projects. Some of these impediments are subject to legislative, regulatory, and technical solutions.

The following discussion points may offer some direction for further investigation:

- Conflicts in Federal Laws Could be Resolved

Analysis has shown that about 70 percent of the laws and decisions directly affecting hydropower licensing and development have occurred since 1970. These laws and decisions give specific authority to states and other federal agencies, such as the Environmental Protection Agency, the Forest Service, the Bureau of Land Management, the Fish and Wildlife Service, the Corps of Engineers and others. This has led to an erosion of FERC's authority to actually control the process and may conflict with the purposes of the Federal Power Act.

- FERC's Ultimate Authority to Run the Process Could be Affirmed

FERC continues to have the responsibility under the Federal Power Act to give "equal consideration" to all competing resources in licensing a hydropower project in the public interest. Seeking to avoid further challenges and lacking a consensus on specific and consistent technical criteria for deciding resource issues in hydropower licensing consultations, environmental assessments, and "equal consideration" evaluations, the FERC has little choice but to accept resource agency positions.

- Consistent Technical Criteria Could be Defined to Reduce Risk

Such criteria are also needed to give some measure of knowable risk for licensees. Since there are no consistent technical criteria for evaluating the need for studies or selecting the study methologies, hydropower developers have no assurance of what studies will be required, how studies are to be conducted or how the results may be used by agencies and the FERC to establish mitigation conditions for licenses or to effect project design or 
operation. This assumes even more importance since more than 50 percent of the articles contained in the hydropower licenses now being issued allow agencies or the FERC to require changes in operation or additional studies at any time during the term of a license.

- Requirement to Begin Immediate Construction Could be Eliminated

Many of the recent license surrenders occured because an originally profitable project lost its profit margin when short term economic conditions changed during the course of the lengthy licensing process. After a license is issued, the statutory time limits for licensees to begin construction or lose their license is 2 years with the possibility of a single 2-year extension. On a case-by-case basis, the 105th Congress has extended this time to begin construction for more than a dozen projects.

- "Look-Behind" Studies on the Success of Mitigation Could be Instituted

Costly environmental mitigation requirements are a part of every hydropower license and relicense issued in recent years. These requirements are based on agency positions or studies using theoretical assumptions and are enforced for the 30 to 50 year life of the license. There is no mechanism to assess the effect of these requirements on the environment. After a few years, there should be an analysis to determine whether the requirements are achieving their intended purpose and elimination or modification of any requirements that do not.

- River Basin Use Assessment Could be Done in the National Interest

The Wild and Scenic Rivers Act gives authority to protect certain segments of rivers or streams from development. At the same time, certain other rivers have been highly developed for many years with canals, locks and dams, water supply reservoirs, recreation lakes and ponds, and hydropower for industrial and municipal use. A comprehensive examination of the use of various river basins in the United States and definition of those appropriate for various types of development is needed. This would indicate the areas where hydropower development would be consistent with the present uses of the river. Enormous savings could be realized by such prescreening of allowable sites. 
- Improved Turbine Technology Could Safely Increase Generation

Any technology must constantly improve to satisfy emerging requirements. Advanced turbine designs could minimize injury or mortality to fish and accomodate instream flow needs more efficiently while allowing continued power production over a wide range of flow conditions. It is also possible that an advanced turbine design could mitigate more than one problem. For example, increasing minimum flows that bypass the power plant can raise the oxygen level in the water downstream from the plant and provide safe bypass of downstream migrating fish. However, because spilled water is not used to generate electricity, this is the most costly mitigation measure imposed on hydropower project. Turbine designs that serve these multiple functions while producing electricity would assist greatly in preserving hydropower's contribution to the energy security of the nation. 
Appendix A

Federal Laws Affecting Hydropower 


\section{APPENDIX A \\ FEDERAL LAWS AFFECTING HYDROPOWER}

Rivers and Harbors Act (1899)

Reclamation Act (1902)

Antiquities Act (1906)

Federal Water Power Act (1920)

Public Utility Act (1935)

Federal Power Act (1935)

Flood Control Act (1937)

Wildlife Restoration Act (1937)

Fish and Wildlife Coordination Act (1958)

Wilderness Act (1964)

Solid Waste Disposal Act (1965)

Water Resources Planning Act (1965)

National Historic Preservation Act (1966)

Wild and Scenic Rivers Act (1968)

National Environmental Policy Act (1969)

Occupational Safety and Health Act (1972)

Water Pollution Control Act (1972)

Marine Protection, Research and Sanctuaries Act

Coastal Zone Management Act

Ports and Waterways Safety Act

Marine Mammal Protection Act

Endangered Species Act (1973)

Energy Supply and Environmental Coordination Act (1974)

Non-Nuclear Energy Research and Development Act

Toxic Substances Control Act (1976)

Federal Land Policy and Management Act

Resource Conservation and Recovery Act

Clean Air Act (1977)

Soil and Water Resources Conservation Act

Endangered Species Act Amendments (1978)

Environmental Education Act

Public Utilities Regulatory Policies Act (1978)*

Crude Oil Windfall Profits Tax Act (1980)*

Department of Energy Organization Act

Eastern Wilderness Act

Federal Pollution Control Act

Mining Claims Rights Restoration Act

Land and Water Conservation Fund Act

Comprehensive Environmental Response, Compensation, and Liability Act

Energy Security Act (1980)* 
Pacific Northwest Power Planning and Conservation Act (1980)

Energy Tax Act (1980)*

Economic Recovery Act (1981)*

Resource Conservation and Recovery Act Amendments (1984)

Environmental Programs Assistance Act

Safe Drinking Water Act Amendments (1986)

Electric Consumers Protection Act (1986)

Clean Air Act (1990)

* Laws providing incentives to small-scale hydropower development. 
Appendix B

Footnotes 


\section{APPENDIX B FOOTNOTES}

1 References used to compile the data presented in this section of the report include the following:

a. Hydroelectric Power Resources of the United States - Developed and Undeveloped, Federal Energy Regulatory Commission (FERC), Washington, DC 20426, January 1, 1992.

b. Dam Site Information Database (Three Volumes), FERC, Office of Hydropower Licensing (OHL), Division of Dam Safety, April 2, 1996.

C. FERC, OHL Hydropower Database. This database includes all documented developed and undeveloped hydrpower sites in the United States. By request, the FERC supplied updated printouts from this database on March 11, 1997, of all federal and non-federal hydropower activity from 1980 through 1996.

d. Annual Energy Review - 1995, Energy Information Administration (EIA), U. S. Department of Energy, Washington, DC 20585, July 1996.

e. Inventory of Power Plants in the United States, EIA, December 1996. f. MEMO, FERC, OHL, from the Division Director - Project Management, to the Office Director, May 14, 1987. This memo details the development of hydroelectric capacity (in Megawatts) from 1911 through 1986 for federal, municipal, utility, non-utility, and cooperative/independent categories of ownership.

g. Compendium of Pumped Storage Plants in the United States, American Society of Civil Engineers, New York, NY, 10017, 1993.

Reference f., Note 1, was used to determine the installed capacity for each year from 1920 through 1950. Reference d., Note 1 (Table 8.8 - page 245 and Table 8.12 - page 253), and Reference a., Note 1 (Table VIII - page xxiv, and Table IX - page XXX), provided the basis for installed capacity for each year from 1950 to 1980. To determine the developed capacity trends from 1980 through 1996, detailed data from Reference c., Note 1, was compiled and compared with the information available from References $a$. and $c$. There are differences between these publications concerning developed hydro capacity. For the 1980-1996 period, Reference $c$. was used as the standard. For preceeding years, reasonable judgements were made where necessary when source data differed.

Data for 1920-1950 were estimated by applying an average plant factor of 50 percent to the installed capacity. Reference $d$. Note 1, provided the basis for the remaining data. For years 1950-88, see Table 8.3, page 235. For years 1989-95, the data from Table 8.3, page 235 (utility), for each year was added to the data for the same years from Table 8.12, page 253 (non-utility).

Reference a., Note 1, Table 10, page 319, and Reference g., Note 1, were used to compile these data. 
References and detailed data used to prepare Figure 1-4 are described in Table 1-1.

6

References and detailed data used to prepare Figure 1-5 are described in Table 1-2.

7 Wood/Waste includes municipal solid waste and solar includes both solar thermal and photovoltaic. See Note 1, Reference d, Table 10.8, page 281 for details.

8 Wood/Waste includes municipal solid waste and solar includes both solar thermal and photovoltaic. See Note 1, Reference d, Table 10.9, page 283 for details.

References and detailed data used to prepare Figure 1-6 are described in Table 1-3.

References and detailed data used to prepare Figure 1-7 are described in Table 1-4.

11 The fossil category includes natural gas, coal, coal waste, anthracite culm, distillate fuel oil, residual fuel oil, jet fuel, petroleum coke, diesel fuel, kerosene, tar, butane, ethane, propane, and other gasses. Reference d., Note 1, provided the basis for these data. For years $1955-88$, see Table 8.8, page 245. For years 1989-95, data from Table 8.8, page 245 (utility), for each year was added to the data for the same years from Table 8.12, page 253 (non-utility).

Reference d., Note 1, Table 8.8, page 245, provided the basis for these data.

Other Renewables include geothermal, municipal solid waste, wood, waste, wind, solar thermal, and photovoltaic. See Note 1, Reference d, Table 10.8, page 281 for details.

The fossil category includes natural gas, coal, coal waste, anthracite culm, distillate fuel oil, residual fuel oil, jet fuel, petroleum coke, diesel fuel, kerosene, tar, butane, ethane, propane, and other gasses. Reference d., Note 1, provided the basis for these data. For years 1955-88, see Table 8.8, page 245. For years 1989-95, data from Table 8.3, page 235 (utility) for each year was added to the data for the same years from Table 8.12, page 253 (non-utility).

Reference d., Note 1, Table 8.3, page 235, provided the basis for these data.

16

Other Renewables include geothermal, municipal solid waste, wood, waste, wind, solar thermal, and photovoltaic. See Note 1, Reference d, Table 10.9, page 283, for details. 
17 Note 1, Reference a., Table 4, pages 147-269, provided the base data used to prepare Tables 1-5 and 1-6. The base data was verified, supplimented, and updated with details provided in References $b$. and $c$.

18

All data presented in this section of the report were compiled from Reference c., Note 1.

19 Based on a detailed review by Richard Hunt Associates, Inc., of every relicense issued by the FERC during the period 1980-1996.

20

An Electric Power Research Institute (Palo Alto, CA) report, Increased Efficiency of Hydroelectric Power, report EM-2407, June 1982, estimated upgrade potential of 2,100 MW at existing, non-federal hydropower plants. Table 2-3 not only shows that new capacity installed at operating projects from 1980 through 1996 is only $341 \mathrm{MW}$, but that 84 percent of this capacity was developed prior to ECPA and no new capacity was installed in 1995 and 1996.

21 An EPRI report, Guide for Assessing Relicensing Risk for Hydropower Projects, Report TR-103284, November 1993, page 3-6, describes the following: no relicensed project had open-ended conditions in 1984; however, immediately after ECPA (1987) 5 percent of all articles in relicenses were open-ended and, by 1991, almost half of the articles in relicenses were open-ended. Further analysis for this report indicates that fully 60 percent of requirements for relicenses today are open-ended.

For hydropower projects, dependable peaking capacity averages about 60 percent of the installed capacity for the 70 peaking projects relicensed during 1980-1996 (total installed capacity $3,803 \mathrm{MW}$, dependable peaking capacity $2,282 \mathrm{MW}$ ).

These data are based on detailed records supplied by the FERC in march 1997 from their data base.

24 The surrendered projects were identified from detailed records supplied by the FERC in March 1997 from their data base and by comparing licenses issued with operating projects identified in the Reference b., Note 1.

The estimated generation loss at each project is based on an assumption that these run-of-river plants will operate at an average 50 percent plant or capacity factor (full capacity operation about half of the time during the year). 
26 The results described here are based on data developed from 1987 to 1994 in a series of Electric Power Research Institute (Palo Alto, CA) studies conducted by Richard Hunt Associates, Inc. The folowing EPRI reports detail the results of these studies: Guide for Developing a Hydro Plant Relicensing Strategy, Volume 2, Report AP-6038, December 1989; Lessons Learned in Hydro Relicensing (1984-1989), Report GS-7324, May 1991; Guide for Assessing Relicensing Risk for Hydropower Projects, Report TR-103284, November 1993; Hydropower Relicensing Studies - Experiences, Costs, and Trends, (Unpublished), January 1994. Richard Hunt Associates, Inc. also contributed similar data for another EPRI report: Water Resource Management and Hydropower: Guidebook for Collaboration and Public Involvement, Report TR-104858, December 1995.

An equation was determined for the "best-fit" curve developed from the data used to prepare Figure 3-11. In 1996 dollars, the equation representing this "best-fit" curve is:

$$
\text { Licensing Cost/\$-Millions) }=(0.401) \mathrm{MW}^{0.548} \text {. }
$$

This equation, adjusted to reflect both the increase in cost over the years and the effects of inflation, was then used to estimate licensing costs for the 1980-1996 period for all new projects receiving licenses and placed in service, new licenses that were subsequently surrendered, and relicenses issued. This equation was also used to predict theoretical costs for future time periods. Future predictions are conservative since future inflation and interest rates were not considered.

An average 25 percent plant factor was used to estimate on-peak generation for the peaking plants (it was assumed that these plants would normally average full capacity operation 25 percent of the time during the year).

The value of the power is based on regional purchase values of on-peak and off-peak electricity as reported in McGraw Hill's Power Markets Week, January 6, 1997. These values ranging from $\$ 0.01 / \mathrm{kWHr}$ (off-peak) to $\$ 0.03 / \mathrm{kWHr}$ (on-peak) are wholesale, spot market values and do not represent the true value of retail electricity (as an example, an average annual value of $\$ 0.0695 / \mathrm{kWHr}$ was recently reported by DOE - Hydropower Facts, July 1996). Therefore, to more accurately represent the true value of power, McGraw Hill's numbers were doubled for use in the calculations for this report.

The equation was developed as follows. A "best-fit" curve was drawn on Figure 3-13 for the plotted data points. An equation was then determined for this "best-fit" line relating project costs over a 30 year period to a given project size. This equation was then used to compute "theoretical" mitigation costs for the same 
88 projects where these data originated. The "theoretical" costs predicted from the equation were then compared to the actual costs for these same projects as a calibration measure. The equation was then adjusted to bring "theoretical" costs in line with actual costs.

In 1996 dollars, the equation representing the calibrated curve is

$$
\text { Mitigation Cost(\$-Millions) }=(0.960) \mathrm{MW}^{0.701} \text {. }
$$

This equation, adjusted to reflect both the increase in cost over the years and the effects of inflation, was then used to estimate mitigation costs for the 1980-1993 period for all relicenses issued. This equation was also used to predict theoretical costs for future time periods. Future predictions are conservative since future inflation and interest rates were not considered.

The FERC supplied a record of total annual charges collected from FERC licensees from 1980 through 1996. Annual charges for post-ECPA years are three times higher than those paid prior to ECPA. The annual charges collected in 1996 were used without considering future inflation or future interest rates to estimate conservative future annual charges.

Solar Energy Research Institute; Reference: The Potential for Renewable Energy An Interlaboratory White Paper, Report SERI/TP-260-3674, Idaho National Engineering Laboratory/Los Alamos National Laboratory/OakRidge National Laboratory/Sandia National Laboratories/Solar Energy Research Institute, Golden, CO, March 1990, Table A-1, page a-5 and text, page A-4. SERl's Estimated Potential Available for Development assumes a much more aggressive Federal $R, R \& D$ program to 1) address and resolve the environmental issues having the most detrimental effect on hydro advancement, and 2) design new equipment an technology to accelerate hydropower development. SERl's projected New Development considers business as usual and development at the most non-controversial and economic sites.

Idaho National Engineering Laboratory, Idaho Falls, ID; Reference: Uniform Guide for U. S. Hydropower Resource Assessment - Hydropower Evaluation Software, DOE/ID-10430.1, 1997. INEL's values for Estimated Potential Available for Development are extrapolated from completed assessments of 28 states using their newly developed assessment software. The project is ongoing and other states are continually being added to the list for assessment.

Energy Information Administration; Reference: Renewable Resources in the U. S. Electricity Supply, EIA, U. S. Department of Energy, Washington, DC, February 1993, Table 9, page 16. 
35 By way of comparison, actual new development at non-Federal projects for the period 1990-1996 is 1,880 MW and only one 0.4 MW project was added in 1996. This new capacity includes newly licensed projects in service and capacity increases at a limited number of relicensed projects. 